\title{
The informed road map to prevention of Alzheimer Disease: A call to arms
}

\author{
Eric McDade 1,2,3, Jorge J. Llibre-Guerra ${ }^{1,2,3}$, David M. Holtzman ${ }^{1,2,3}$, John C. Morris ${ }^{1,2,3}$ and Randall J. Bateman ${ }^{1,23^{*}}$ (D)
}

\begin{abstract}
Alzheimer disease (AD) prevention trials hold the promise to delay or prevent cognitive decline and dementia onset by intervening before significant neuronal damage occurs. In recent years, the first AD prevention trials have launched and are yielding important findings on the biology of targeting asymptomatic AD pathology. However, there are limitations that impact the design of these prevention trials, including the translation of animal models that recapitulate key stages and multiple pathological aspects of the human disease, missing target validation in asymptomatic disease, uncertain causality of the association of pathophysiologic changes with cognitive and clinical symptoms, and limited biomarker validation for novel targets. The field is accelerating advancements in key areas including the development of highly specific and quantitative biomarker measures for AD pathology, increasing our understanding of the course and relationship of amyloid and tau pathology in asymptomatic through symptomatic stages, and the development of powerful interventions that can slow or reverse AD amyloid pathology. We review the current status of prevention trials and propose key areas of needed research as a call to basic and translational scientists to accelerate AD prevention. Specifically, we review (1) sporadic and dominantly inherited primary and secondary AD prevention trials, (2) proposed targets, mechanisms, and drugs including the amyloid, tau, and inflammatory pathways and combination treatments, (3) the need for more appropriate prevention animal models and experiments, and (4) biomarkers and outcome measures needed to design human asymptomatic prevention trials. We conclude with actions needed to effectively move prevention targets and trials forward.
\end{abstract}

Keywords: Alzheimer disease, Clinical trials, Primary and secondary prevention

\section{Background}

In the absence of highly effective disease-modifying treatments and against a backdrop of an aging population, the number of adults with dementia worldwide is projected to more than triple by 2050 [1-3]. A prevention treatment delaying the onset of Alzheimer disease (AD) dementia by five years would result in a $41 \%$ lower prevalence and a reduction in personal and societal costs of about $40 \%[4,5]$.

\footnotetext{
* Correspondence: batemanr@wustl.edu

'Department of Neurology, Washington University in St Louis, 660 S. Euclid Avenue, Campus Box, St Louis, MO 8111, USA

${ }^{2}$ Knight Alzheimer's Disease Research Center, Washington University School of Medicine, St. Louis, MO 63110, USA

Full list of author information is available at the end of the article
}

To date, trials in persons with symptomatic AD (a term that encompasses mild cognitive impairment due to $\mathrm{AD}$ and $\mathrm{AD}$ dementia) [6] largely have targeted amyloid-beta $(\mathrm{A} \beta)$, the earliest contributor to AD pathophysiology [79]. Many of these trials had major limitations, including little impact on biology (too little) or treating symptomatic $\mathrm{AD}$ after neurodegeneration and tau pathology is advanced (too late). Some classes, such as $\beta$-site amyloid precursor protein cleaving enzyme (BACE) inhibitors and $A \beta$ antibodies, substantially engaged their targets, but failed to demonstrate a clear clinical benefit in phase 3 trials of symptomatic AD [10-16].

Identifying and demonstrating clear disease-modifying treatments for $\mathrm{AD}$ has continued to be elusive. Until 
drug classes demonstrate a consistent substantial change in the clinical disease course, potential targets are both numerous and uncertain and include $A \beta$ (plaques, surrounding protofibrils/oligomers, monomers, and $A \beta$ modifications such as pyroglutamate, truncations, and amino acid substitutions), tau (tangles, oligomers, seeding, aggregation, phosphorylation, acetylation), inflammation (microglia, activated astrocytes, complement), neurodegeneration (protein homeostasis, vascular transport mechanisms, cytokines), apolipoprotein $\mathrm{E}$ (which impacts $A \beta$, tau, inflammation, and neurodegeneration), and the neurovascular unit (capillary/neurons/astrocytes/pericytes). Ongoing AD trials seek to engage these myriad targets but are limited in number, speed, and scope, resulting in too few shots on goal. Many newly developed drugs do not proceed to clinical trials due to the uncertainty of success combined with the untenable cost, duration, and size of trials, which sequester pharma resources [17].

Another major issue with current $\mathrm{AD}$ trials may be related to the selection of participants too late in the disease course or incorrect target selection according to disease stage. Further, even if current symptomatic trials are successful with the targeted goals of $25-40 \%$ slowing of disease progression, millions of patients and families will still have to endure slow progressive loss of cognitive abilities and of daily function, resulting in increasing disability and dependence. Therefore, it would be optimal to intervene before substantial cognitive impairment has occurred. Advancements are needed to improve the chances of clinical trial success, including improved target and drug mechanism validation, identification of those at risk of $\mathrm{AD}$, rapid screening and enrollment into prevention trials, and clear proof of concept studies that demonstrate significant biological engagement $[18,19]$.

The AD field is rapidly advancing our ability to implement these improvements with recent discoveries in identifying pre-symptomatic stages of $\mathrm{AD}$, quantitative biomarkers to measure the magnitude of disease modification, and simple and fast screening blood based biomarkers to identify at risk individuals [20-22]. The recent development of biomarkers to track $\mathrm{AD}$ pathology [23-25] has led to a better understanding of the AD spectrum of disease stages, having significant implications for early treatment and prevention trial enrollment and for back-translation to preclinical studies. As a result, the search for therapeutic agents has moved earlier in the disease continuum into the asymptomatic stage of $\mathrm{AD}$, which is defined by the presence of $\mathrm{AD}$ pathology without clinically apparent symptoms, and the field has launched the first generation of prevention trials (Fig. 1). We define primary prevention as an intervention that is implemented before evidence of disease or injury (i.e., before amyloid or tau pathology or neurodegeneration). Secondary prevention is treating pathologic disease in asymptomatic individuals with subclinical forms of the disease (e.g. cognitively unimpaired but $\mathrm{AD}$ biomarker-positive, identifying those with increased risk for future symptomatic AD). Several primary and secondary AD prevention trials currently are in the planning stages, have begun enrolling subjects, or have just concluded (Fig. 2). Although operational implementation of $\mathrm{AD}$ prevention trials has been feasible, multiple challenges need to be addressed to optimize

\section{9/2020 - Tau Drug Trials, Combination Therapy, Primary Prevention}

2017 - Prevention trials with oral secretase inhibitors

2014 - Prevention trials targeting at-risk individuals

2012 -first prevention trial against amyloid-beta is launched

2012 - A $\beta$ lowering mutation discovered which dramatically protects against Alzheimer's

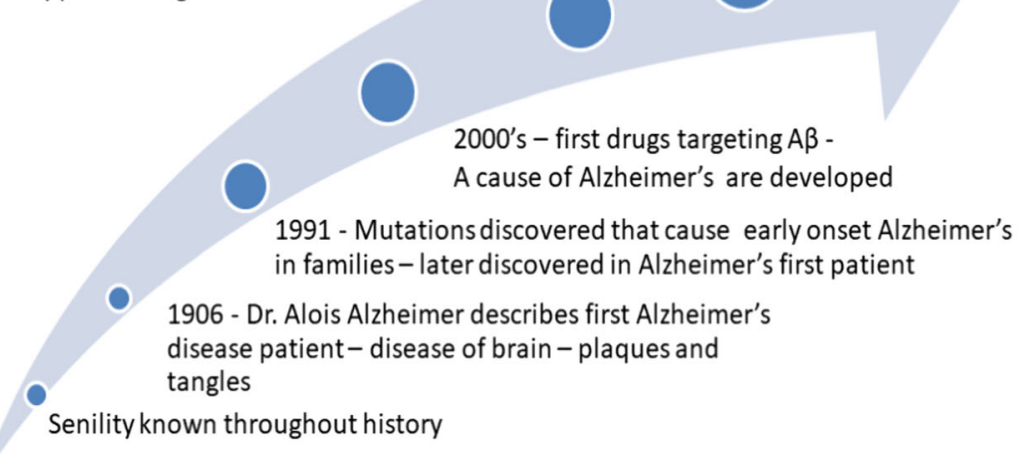

Fig. 1 A brief history of AD prevention trial development 




Fig. 2 Alzheimer's disease prevention trials and targets: Prevention trials and target agents for treatment of Alzheimer's disease in 2020 (from ClinicalTrials.gov as of August 24, 2020). The inner ring shows prevention trials agents; the outer ring presents lifestyle prevention trials. AD therapeutics interventions were classified according with the terminology of the Common Alzheimer's and Related Dementias Research Ontology (CADRO). Lifestyle interventions ( $N=18)$, Drug Targets $(N=37)$

trial design. These include validation of targets for primary or secondary prevention stages of the disease, improved understanding of biomarker progression leading to clinical symptoms, accurate translation of animal and in vitro models to human studies, and development of models for AD-related inflammation. Here, we review the current field of prevention trials by therapeutic target and propose key areas of research needed as a call to basic and translational scientists to improve the design and interpretation of AD prevention trials.

\section{Review of amyloid prevention approaches}

The amyloid hypothesis proposes that amyloid plaques formed by aggregates of the $A \beta$ peptide generated by proteolytic cleavage of amyloid precursor protein (APP) are central to AD pathology [26]. Increased levels or ratios of $A \beta 42$ induce $A \beta$ amyloid fibril formation [27] and, in late onset $\mathrm{AD}$, impaired clearance of $\mathrm{A} \beta$ leads to the age-associated risk of amyloidosis and $\mathrm{AD}$ [28]. The accumulated $A \beta$ amyloid fibrils develop into senile plaques, causing local, plaque-associated neurotoxicity and later facilitation of the spread of tau pathology [29]. The oligomeric and protofibrillar species are hypothesized to be the most toxic forms [30] and may facilitate tau hyperphosphorylation, disruption of proteasome and mitochondrial function, dysregulation of calcium homeostasis, synaptic failure [31], and glial cell activation [31, 32]; leading to neuronal cell death, neurodegeneration, and cognitive impairment. However, it is unlikely that $A \beta$ accumulation directly leads to marked synaptic loss and neuronal cell death as substantial accumulation of $A \beta$ occurs in the human brain and in animal models of $A \beta$ accumulation without significant synaptic loss and neuronal death. $A \beta$ aggregates induce downstream changes such as tau accumulation and inflammation that are more proximate to synaptic failure and cell death. $A \beta$ accumulation appears to be the first pathogenic event leading to subsequent downstream pathological changes and remains an important target of AD prevention trials.

The amyloid hypothesis has been tested in multiple therapeutic strategies aimed at targeting $A \beta$ in the brain. The approaches include $A \beta$ active or passive immunization [33-37], and $\gamma$ - and $\beta$-secretase inhibitors or modulators $[10,38,39]$. Despite the scientific strength of the amyloid hypothesis, to date clinical trials targeting $A \beta$ have failed to clearly demonstrate clinical benefit $[14,36]$ with the consequence that the amyloid hypothesis has been questioned [7, 40, 41]. However, there are several reasons that may account for these trial failures including treating too late in the disease course, inadequate dosing or target engagement, and incorrect specific A $\beta$ target (e.g. monomer, oligomer, or plaque) [40, 42].

Because amyloid deposition is one of the first events beginning 20 years or more before AD dementia, administering $A \beta$ therapies at symptomatic or advanced stages of ongoing neurodegeneration may provide little clinical benefit. $A \beta$ therapeutic agents are ideal candidates for primary or secondary prevention strategies before the development of substantial tau tangles, inflammation, and neurodegeneration as they may prevent the onset of dementia. This concept is supported by recent results from the Dominantly Inherited Alzheimer Network 
Trials Units (DIAN-TU), where significant reduction of brain amyloid deposition by gantenerumab, a monoclonal antibody targeting aggregated $A \beta$, had strong effects in downstream biomarkers. Compared with placebo, participants treated with gantenerumab showed significant reductions in CSF total tau and p-tau181 and slowed increases in CSF NfL. In support of the concept of a need for earlier intervention of $A \beta$ therapeutics, the effect of gantenerumab on plaque reduction and downstream biomarkers of tau pathology and neuronal injury appeared to be larger in the asymptomatic group vs. the symptomatic group-though the small number of participants limited the statistical power of these findings. Although no cognitive or clinical benefit was observed, these findings suggest that removal of amyloid plaques may be a viable strategy in preventing or slowing the biological progression of $\mathrm{AD}$ if introduced at an optimal time [43].

Trials aimed to prevent $A \beta$ aggregation will require many years to obtain biomarker readouts and even longer to determine if prevention of $A \beta$ aggregation delays or stops symptomatic AD phases. Primary prevention trials will require participant enrollment for long periods and academic, private, and government partnerships will be key elements for the development and successful completion of such trials. Several efforts are underway for primary prevention trials, including DIAN-TU, which will use anti-A $\beta$ agents in the world's first primary prevention trial in $\mathrm{AD}$. Because of the uncertain outcomes of $\mathrm{AD}$ prevention studies, preclinical studies that can minimize risk by defining the optimal time to introduce amyloid specific therapies or the expected effects on tau and inflammation by preventing or removing amyloid plaques are high priority goals.

Table 1 summarizes ongoing and planned $A \beta$ prevention trial therapies that are currently being tested in symptomatic stages but that also have a strong rationale for application in prevention studies. Given the large number of $\mathrm{A} \beta$ specific clinical trials that have been conducted without clear success to date, below we summarize priorities for animal model studies to increase the probability of success in $\mathrm{AD}$ prevention studies [46].

\section{Animal models re-create some, but not all aspects of AD in humans}

Nearly 200 mouse models that have various aspects of AD pathology (https://www.alzforum.org/researchmodels/search) have been generated to explore disease pathophysiology and identify various therapeutic strategies. Animal models constitute one of the most important research tools in basic research for $\mathrm{AD}$ and have resulted in key findings for AD. Current models either develop $A \beta$ plaques or neurofibrillary tangles
(NFTs), or in some cases a combination of both pathologies, but these transgenic mice do not exhibit the full spectrum of AD pathophysiology [47, 48]. The amyloid pathology is different in AD models compared to the human $\mathrm{AD}$ pathology, with differences in ultrastructure, amount and kinds of amyloid and in the binding to amyloid PET tracers. Moreover, these models do not replicate the full range of copathologies often present in sporadic $A D$, including vascular disease, Lewy body disease, TDP-43, or hippocampal sclerosis. Therefore, current models do not recapitulate the complexity of late-onset $\mathrm{AD}$. In addition, sporadic $\mathrm{AD}$ arises from the interaction between genetic and environmental factors, but current models are based on genetic mutations and do not replicate key lifestyle risk factors linked to symptomatic onset and disease progression. These differences between $\mathrm{AD}$ models and human $\mathrm{AD}$ may partly explain how therapeutic strategies that clearly work in mouse models do not replicate the pathological findings in the model or translate into positive results in human $\mathrm{AD}$ clinical trials. Finally, many of the interventional studies with $A D$ models implement treatment at a much earlier stage, usually before substantial pathology is established, while human clinical trials in symptomatic AD implement intervention only after the amyloid-induced pathological cascade has been established.

\section{Timing of $A \beta$ intervention}

$A$ major issue with the failure of some $A \beta$ interventions may be related to enrolling participants too late into the disease course (i.e., when symptomatic AD is manifest, even at its earliest stages), when neurodegeneration and synapse loss already has occurred and $A \beta$ pathology has been fully established over a after two-decade period of growth. At these symptomatic stages, $A \beta$ plaque removal may have little effect on cognition. Ideally, anti-A $\beta$ agents should be introduced early enough to avoid tau aggregation and the alteration of the CNS inflammatory response as, once initiated, these processes may be autonomous from amyloid. The concept of initiating $A \beta$ interventions in primary and secondary prevention trials before later stages of $\mathrm{AD}$ is shown in Fig. 3.

In order to inform the design of these prevention studies, AD mouse models are needed that recapitulate the human disease of sequential progressive steps of amyloid, soluble tau, hypometabolism, atrophy, aggregated tau and tangles culminating in neurodegeneration, cognitive and clinical impairment resulting in death. Models which can better recapitulate the sequential stages of human AD should then be used to test interventions before, during, and after pathological target development to inform about the stage 
Table 1 Current $A \beta$ therapeutics with rationale for $A D$ prevention clinical trials

\begin{tabular}{|c|c|c|c|c|c|c|c|}
\hline Class & Compound & $\begin{array}{l}\text { Current } \\
\text { status }\end{array}$ & Disease Stage & $\begin{array}{l}\text { Trial } \\
\# / \text { Names }\end{array}$ & $\begin{array}{l}\text { Sample } \\
\text { size }\end{array}$ & $\begin{array}{l}\text { Trial } \\
\text { Outcome } \\
\text { measures }\end{array}$ & Evidence from clinical studies \\
\hline \multirow[t]{8}{*}{$\begin{array}{l}\text { Immuno- } \\
\text { therapy }\end{array}$} & $\begin{array}{l}\text { ABvac } 40 \\
\text { (active }^{\text {vaccine) }}\end{array}$ & Phase 2 & Mild AD & NCT03461276 & $120^{\mathrm{b}}$ & $\begin{array}{l}\text { Safety and } \\
\text { immune } \\
\text { response }\end{array}$ & $>90 \%$ immune response [44] \\
\hline & $\begin{array}{l}\mathrm{ACl}-24 \text { (active } \\
\text { vaccine) }\end{array}$ & Phase 2 & $\begin{array}{l}\text { Asymptomatic } \\
\text { Down Syndrome }\end{array}$ & $\begin{array}{l}\text { NCT04373616 } \\
\text { ACl-24-0701 }\end{array}$ & $72^{\mathrm{b}}$ & $\begin{array}{l}\text { Safety and } \\
\text { MRI }\end{array}$ & $\begin{array}{l}\text { Initial formulation with suboptimal immune } \\
\text { response }\end{array}$ \\
\hline & BAN2410 & $\begin{array}{l}\text { Phase 2/ } \\
3\end{array}$ & $\begin{array}{l}\text { Asymptomatic } \\
\text { with low or } \\
\text { higher amyloid } \\
\text { plaque load }\end{array}$ & $\begin{array}{l}\text { NCT01767311 } \\
\text { AHEAD } \\
(\text { A345) }\end{array}$ & 856 & $\begin{array}{l}\text { Safety and } \\
\text { Cognitive } \\
\text { change }\end{array}$ & Active, results not yet available \\
\hline & CAD106 & Phase 3 & $\begin{array}{l}\text { Asymptomatic } \\
\text { sporadic AD }\end{array}$ & NCT02565511 & 480 & $\begin{array}{l}\text { Cognitive } \\
\text { change }\end{array}$ & Terminated, results not yet available \\
\hline & Crenezumab & Phase 2 & $\begin{array}{l}\text { Asymptomatic } \\
\text { DIAD }\end{array}$ & NCT01998841 & 252 & $\begin{array}{l}\text { Cognitive } \\
\text { change }\end{array}$ & $\begin{array}{l}\text { Low to High dose being tested in Colombian } \\
\text { kindred (PSEN-1_E280A) }\end{array}$ \\
\hline & Gantenerumab & $\begin{array}{l}\text { Phase 2/ } \\
3\end{array}$ & $\begin{array}{l}\text { Asymptomatic } \\
\text { DIAD; } \\
\text { Mild AD }\end{array}$ & $\begin{array}{l}\text { NCT01760005 } \\
\text { NCT03443973 }\end{array}$ & $\begin{array}{l}73 \\
982\end{array}$ & $\begin{array}{l}\text { Biomarker, } \\
\text { Cognitive, } \\
\text { and Clinical } \\
\text { change }\end{array}$ & $\begin{array}{l}\text { Tau and neurodegeneration biomarker } \\
\text { improvements with lowered CSF tau, p-tau181, } \\
\text { and NfL. No clinical benefit in DIAD at low dose. } \\
\text { High dose continued testing in DIAN-TU OLE } \\
\text { prevention trial }\end{array}$ \\
\hline & Solanezumab & Phase 3 & $\begin{array}{l}\text { Asymptomatic } \\
\text { DIAD completed } \\
\text { Asymptomatic } \\
\text { sporadic AD }\end{array}$ & $\begin{array}{l}\text { NCT01760005 } \\
\text { NCT02008357 } \\
\text { A4 }\end{array}$ & $\begin{array}{l}71 \\
1150^{\mathrm{b}}\end{array}$ & $\begin{array}{l}\text { Biomarker, } \\
\text { Cognitive, } \\
\text { and Clinical } \\
\text { change }\end{array}$ & $\begin{array}{l}\text { No tau or neurodegeneration biomarker } \\
\text { improvements or clinical benefit in DIAD on low } \\
\text { dose; asymptomatic sporadic AD prevention } \\
\text { trial (A4) ongoing with higher dose }\end{array}$ \\
\hline & $\begin{array}{l}\text { UB-311 (active } \\
\text { vaccine) }\end{array}$ & Phase 2 & Mild AD & NCT02551809 & 43 & $\begin{array}{l}\text { Safety and } \\
\text { immune } \\
\text { response }\end{array}$ & $\begin{array}{l}>90 \% \text { immune response with a good safety } \\
\text { profile. }\end{array}$ \\
\hline \multirow[t]{2}{*}{$\begin{array}{l}\text { Small } \\
\text { Molecule }^{c}\end{array}$} & $\begin{array}{l}\text { PQ912 } \\
\text { (Inhibitor of } \\
\text { glutaminyl } \\
\text { cyclase) }\end{array}$ & Phase 2 & Early AD & NCT03919162 & $414^{b}$ & $\begin{array}{l}\text { Safety, PK } \\
\text { and clinical } \\
\text { outcomes }\end{array}$ & $\begin{array}{l}\text { Good safety profile; trends for cognitive benefit } \\
\text { [45]. }\end{array}$ \\
\hline & $\begin{array}{l}\text { BACEi } \\
\text { JNJ-54861911 } \\
\text { MK-8931 } \\
\text { (verubecestat) } \\
\text { E2609 } \\
\text { (Elenbecestat) } \\
\text { CNP520 } \\
\text { LY3314814 } \\
\text { Lanabecestat }\end{array}$ & Phase 3 & $\begin{array}{l}\text { Asymptomatic/ } \\
\text { Early AD }\end{array}$ & $\begin{array}{l}\text { NCT02569398 } \\
\text { NCT01953601 } \\
\text { NCT03036280 } \\
\text { NCT03131453 } \\
\text { NCT02245737 }\end{array}$ & $\begin{array}{l}557 \\
1454 \\
2212 \\
1145 \\
2218\end{array}$ & $\begin{array}{l}\text { Negative } \\
\text { effects in } \\
\text { cognition, } \\
\text { decrease AB }\end{array}$ & $\begin{array}{l}\text { Clinical studies halted due to safety concerns } \\
\text { with rapid mild negative effects in cognition } \\
\text { which may be reversable. }\end{array}$ \\
\hline
\end{tabular}

The table represents the recent approaches to $A \beta$ therapeutics highlighting new mechanisms to be tested on prevention trials



${ }^{b}$ Potential agents for primary/secondary prevention. Proposed potential as a prevention therapy is based on how likely the known mechanism of action aligns with the disease stage of $A \beta$-pathology (prevent $A \beta$ aggregation or $A \beta$ plaques removal), the known side effect profile (long term treatments likely required) and the available data on clinical efficacy

'Estimated enrollment

of human disease to design clinical studies. Few interventions targeting $A \beta$ in animal models were tested to determine if they remove existing fully established amyloid plaques as opposed to determining if they prevent further increases in plaques. A recent study highlighted this potential utility by demonstrating that APP secretase inhibitors were primarily effective in preventing rather than significantly reversing $A \beta$ plaque pathology [49]. Had there been similar studies for other secretase inhibitors $(\gamma$ and $\beta$ ), clinical trials could have been designed toward earlier prevention stages and possibly utilized lower dosing, which is a key factor, as the secretase inhibitors have safety issues that may be dose dependent.

\section{Summary}

Based on the multitude of clinical trials that have been conducted with $A \beta$ targeted approaches, $A \beta$ therapies do not have a large clinical effect in symptomatic $A D$ but may delay or even prevent symptomatic $\mathrm{AD}$, if introduced sufficiently early in the asymptomatic disease process. Recent findings with immunotherapies indicate that targeting specific types of fibrillar $A \beta[50,51]$ can have a large biological effect in asymptomatic prevention 


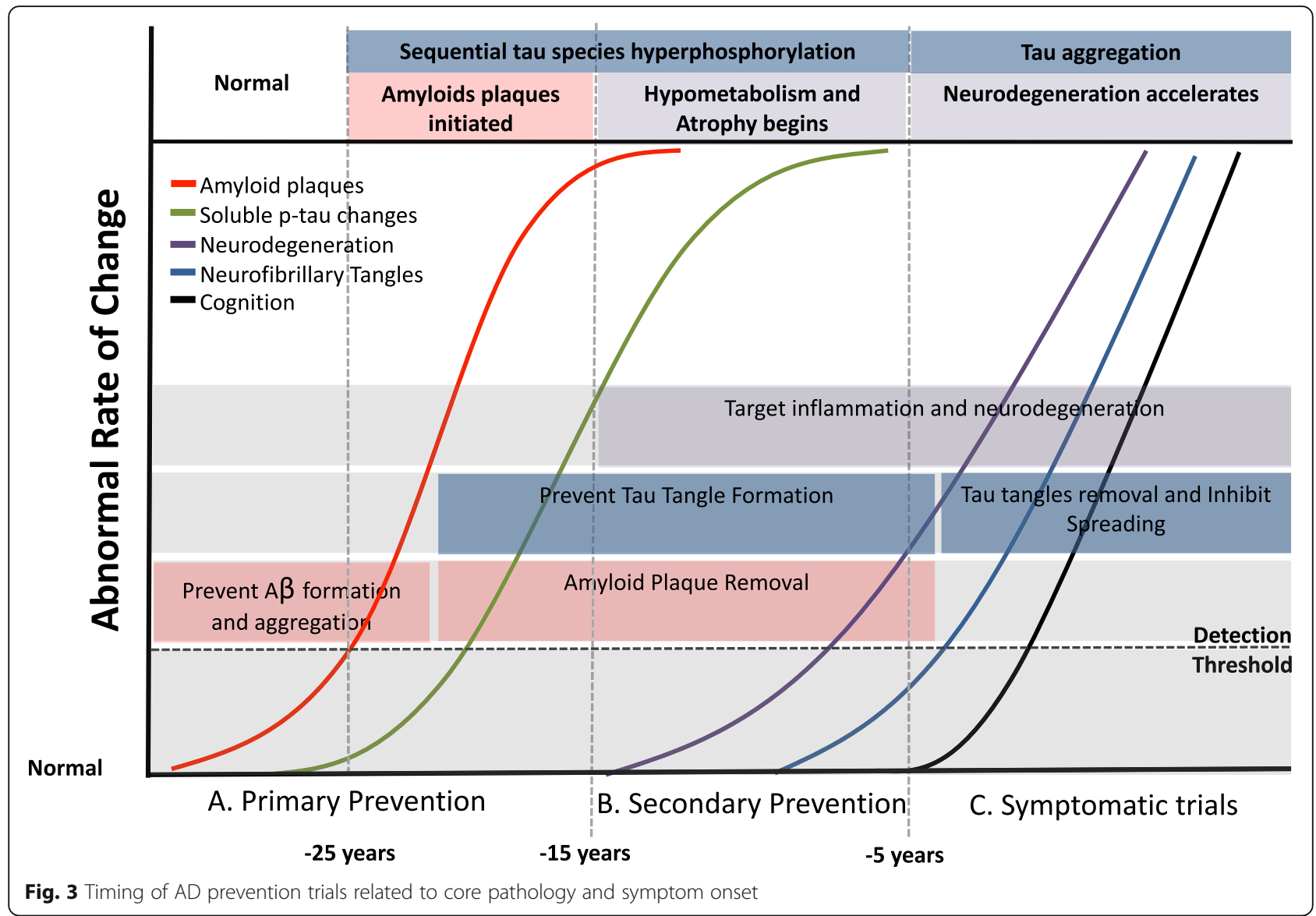

trials [52]. However, much remains to be understood with these interventions, particularly whether the clinical benefit is mediated from a direct amyloid reduction, indirect reduction of soluble or aggregated forms of tau, or an interaction with the CNS immune system and slowing neurodegeneration. Basic and translational sciences should accelerate development of appropriate amyloid prevention models, identify amyloid and downstream prevention biomarkers, and test amyloid interventions under conditions that enables translation to prevention trials.

\section{Review of Tau prevention approaches}

Hyperphosphorylated, intracellular insoluble tau in the form of NFTs is pathognomonic of AD [53, 54]. Tau pathology in the brain correlates much more highly with clinical status and dementia than do amyloid plaques, atrophy, or perturbations of glucose metabolism [55, 56]. Tau aggregation correlates with onset, progression of cognitive symptoms, and focal neurologic symptoms (e.g., memory, visuospatial function and language) [57]. CSF total-tau (i.e. all soluble tau regardless of phosphorylation) and phosphorylated-tau (i.e. p-tau with specific phosphorylation sites) isoforms predict clinical onset and tau in blood mirrors these results [58]. A molecular structural description of tau pathology demonstrates identical structures in Dominantly Inherited AD (DIAD) and sporadic $\mathrm{AD}$ (sAD), which differs from non-AD tauopathies [59]. Normal forms of tau function as a regulator of axonal remodeling are actively regulated and produced, and extracellular tau has increased production correlating with amount of amyloid plaques [60]. Importantly, as it relates to prevention trials, tau soluble changes begin near amyloid plaque pathology, 20 years before symptom onset, while the aggregated tau pathology measured by tau PET appears at symptom onset (see Fig. 3) [21, 61-63]. This provides a window of opportunity to intervene in tau before symptom onset and the growth of tau tangle aggregation.

Tau targets present challenges due to the complexity of the tau target and pathological changes with a large number of post-translational modifications, including phosphorylation, and dozens of fragments and alternative forms [64]. Unfortunately, the leading mouse models that develop tau pathology (e.g., P301S, P301L) used in preclinical testing of anti-tau therapies have frontotemporal lobar degeneration (FTLD) tauopathies which are structurally different from AD tauopathy, limiting their 
predictive power for AD clinical trials [65, 66]. Further, we know much less about the longitudinal changes of tau pathology due to limited kinds of biomarkers and lack of understanding of the relationship between the soluble tau measures in CSF and blood and the aggregated tau measured by tau PET. For example, the tau in CSF is N-terminal to mid-domain, while the tau present in tau aggregates and NFTs are comprised of the Cterminal region, so they are distinctly different parts of the protein and pathophysiology.

Our understanding of sequential changes in tau biomarkers identifying tau stages in DIAD and sAD has improved over the past few years, enabling the ability to detect drug effects on biomarker outcomes [67, 68], including at the prevention stage. A near-term need is to improve target validation of tau in the asymptomatic versus symptomatic stages and to understand the relationship between soluble tau and tau aggregation. One possibility is that aggregation of amyloid causes a physiologic response of increased tau production and soluble secretion of hyperphosphorylated forms that increases the risk of tau intracellular aggregation some two decades later that is manifest at the time of progression to symptomatic AD. The diverse mechanisms by which aggregated tau may directly or indirectly be related to neuronal toxicity require additional research in order to improve the predictability of therapies targeting aggregated forms of tau.

\section{Tau therapies: current state}

In addition to the strong rationale for targeting tau to treat $\mathrm{AD}$ (and other neurodegenerative tauopathies), the lack of success of $A \beta$-specific therapies has intensified the search for tau therapies. Recent comprehensive reviews of tau therapies provide in-depth assessments [69]. Table 2 summarizes current approaches to tau interventions with a focus on prevention mechanisms to prevent or remove hyperphosphorylated or aggregated tau. Lowering soluble forms of tau is not synonymous with removing aggregated tau, and provides a twenty year window of opportunity to prevent the formation of intracellular NFTs as the key pathological form of tau in AD [76].

With recent advances in the understanding of tau, multiple novel tau therapeutics have advanced to earlystage clinical trials. New classes of drugs include antibodies to different epitopes and forms of tau (monomeric, phosphorylated, aggregated), genetic treatments to lower tau species (antisense oligonucleotides [ASOs], small interfering RNA [siRNA], and adeno-associated viral [AAV] vectors), and small molecules to inhibit or reverse aggregation $(\mathrm{O}-\mathrm{GlcNAc}$ inhibitors and direct aggregate binders). These powerful novel treatment mechanisms appear promising for testing in the $A D$ population, as demonstrated by success in other disease populations and in preclinical models. For example, ASOs for spinal muscular atrophy have demonstrated the ability to change the course of the disease [77-79], and anti-tau therapies have demonstrated a reversal of neurodegeneration in tauopathy mouse models [80, 81]. Therefore, diversified testing of tau targets and mechanisms are essential to addressing target validation. Currently there are approximately 20 active tau therapeutic programs in human studies, primarily in early phase I-II trials (Alzforum, Aug 23, 2020), with the majority being passive or active immunotherapies targeting different amino acid sequences of the soluble or insoluble tau protein (Table 2). The diversity of targets reflects, in part, an incomplete understanding of how the tau protein contributes to neurodegeneration. In this section we discuss the current state of tau therapeutics in the context of recent clinical research and propose basic and translational research needed to help accelerate the discovery of effective therapies for the prevention of AD.

\section{Reverse translation of tau and clinical symptoms of $A D$ to models}

Although mutations of the microtubule associated protein tau (MAPT, the gene encoding the tau protein), have been identified as a cause of familial frontotemporal lobar dementia-tau (FTLD-tau) [82], these mutations do not cause AD. Additionally, tau aggregates of $\mathrm{AD}$ [83] and FTLD (e.g., Pick's disease) [84] are distinctly different in anatomical distribution and their clinical expression. In addition to $\mathrm{AD}$ and Pick's disease, there are other clinical tauopathies (e.g., progressive supranuclear palsy, corticobasal degeneration, chronic traumatic encephalopathy), all which have distinct clinical symptoms and pathological forms of tau, highlighting the need for translational studies to account for differences between the tauopathies. Further, it is important to note that in $\mathrm{AD}$, the spread of tau appears fundamentally linked to the presence of $A \beta$-plaques. Thus, translational studies focusing on the therapeutic targeting of tau, especially if involving mechanisms preventing tau spread, should include models that better approximate the environment of clinical AD by considering the interactions between $A \beta$ and tau.

Another challenge is that soluble extracellular (CSF/ plasma) tau increases years before insoluble/aggregated tau is detected by tau PET, and it is important to understand whether there are similar patterns in animal models. If there are similar findings in preclinical models, these would offer an opportunity to explore the potential toxicity of soluble tau $[85,86]$ proteins. However, there is minimal information available from animal models of AD tauopathy regarding how these CSF and plasma measures of p-tau and t-tau change [87-89]. 


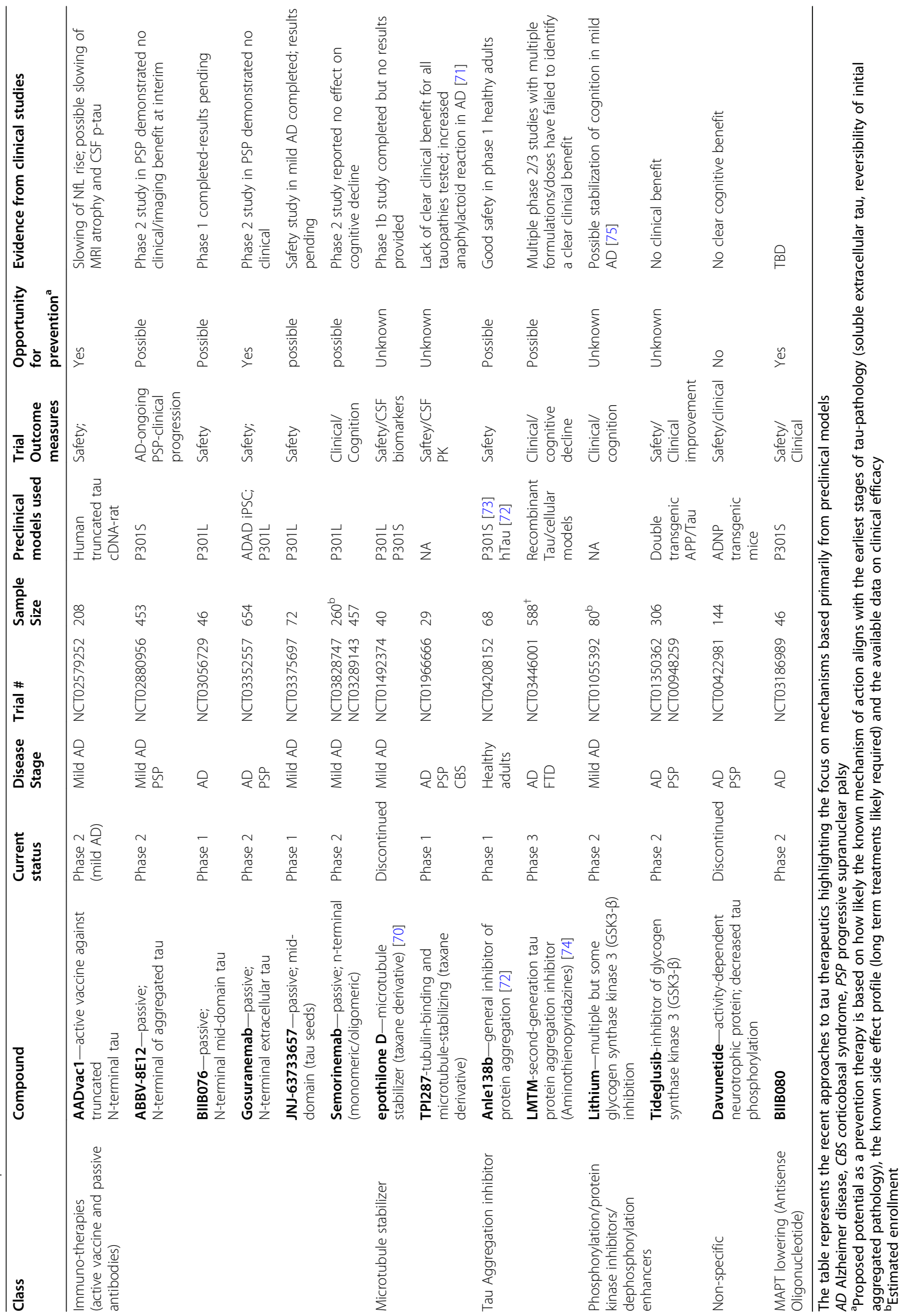


This pattern of early soluble p-tau elevations many years prior to both cognitive decline and the development of aggregated tau indicates that (1) further mechanistic studies linking $A \beta$ with the cellular response to tau generation are an important point for possible therapeutic focus and (2) understanding the critical links between soluble and insoluble tau pathology could have important therapeutic indications, especially for prevention. Likewise, in human studies, although the number of available tests for measuring soluble and aggregated tau has increased dramatically over the past 5 years [21, 23, $59,61,90]$, there remains a significant gap in the understanding of how soluble measures of tau are related to NFT as measured by PET. Because most studies in humans are currently cross-sectional or represent endstage $\mathrm{AD}$ (e.g. post-mortem studies) there is a limited understanding of how changes in soluble tau predict or are related to the evolution of aggregated tau [91]. However, the DIAN study indicates that p-tau increases approximately 20 years before tau PET increases [59]. Animal models of tau, with a much shorter time scale and more precise understanding of the development of aggregated tau, could help to overcome some of the limits by linking measures of soluble tau to immunohistochemical measures of aggregated tau along the period of development of tau tangle pathology. For example, models have demonstrated increased tau with amyloid plaques and no tau pathology [87]. This type of work in animal or cellular models would help in planning tau therapeutic trials based on specific measures of soluble tau being targeted and how those targets relate to preventing NFT pathology.

It is important that therapeutic translational model studies should attempt to simulate the specific forms of tauopathies as closely as possible. As an example, an immunotherapy that is developed to recognize specific sites of phosphorylation or conformation of aggregated tau may have variable translatability to symptomatic AD depending on whether a transgenic MAPT (e.g., P301L mutation resulting in an increased propensity for aggregation of 4-repeat (4R) tau or the R406W mutation which recapitulates $\mathrm{AD}$ tau pathology) mutation model is used or whether an injection model of tau aggregates isolated from AD brain homogenates is used. Similarly, a therapy developed to decrease the aggregation of tau or potentially block the trans-synaptic spread and templatebased 'seeding' of tau may have important differences based on the proportion of 3-repeat (3R) to 4-repeat (4R) tau of the host animal or cellular model and the subsequent translation to the type of tauopathy being tested in humans. Recent post-mortem work has linked the seeding activity of tau to differences in the pattern of phosphorylation and the rate of clinical progression [92] of patients. This suggests that work in cellular and animal models using tau isolated from AD patients should also take into account the heterogeneity related to the source of tissue as this could potentially affect the outcomes of studies based on the prevention of tau spread or seeding.

\section{Narrowing the gap-translating biomarkers between clinical and translational models}

Developments in clinical diagnostics of tau over the past 20 years have now enabled a much more favorable environment for the bidirectional translation of preclinical and clinical studies. Although the detection of soluble tau from the CSF [93-95] of patients with AD has been available for over 20 years, the majority of information on the links between tau pathology and $\mathrm{AD}$ has been based on post-mortem studies [55, 56, 96]. Because of the links between NFT pathology and the clinical/cognitive impairment of $\mathrm{AD}$, most previous trials targeting tau have (1) been in symptomatic populations, and (2) have had clinical outcomes as the measure of efficacy (Table 2). In this scenario, the success of a tau therapy relies on the ability of a single-drug, single-target approach to have a substantial treatment effect on advanced stages of $\mathrm{AD}$ pathology, when tau aggregation is accelerating. Yet in most instances, preclinical studies of tau are based on more precise measurements at the tissue level (e.g. elimination, modifications, cell-cell interaction, kinase regulation) that are not translatable to human studies except, in some instances, at postmortem [92, 97]. However, even when a similar method can be applied to both preclinical and post-mortem $\mathrm{AD}$ samples (e.g., immunohistochemical methods, single-cell RNA expression, tau PET), there often are important differences in the stage of disease/tau-pathological evolution when these methods are applied in the two different scenarios, potentially limiting the translatability.

One of the advantages of some animal models that develop tauopathy such those that express the P301S or P301L mutations in tau is that the mice develop not only aggregated tau pathology but also neurodegeneration with brain atrophy, synaptic and neuronal loss, and a strong neuroinflammatory responses in the tauopathy brain regions. This is similar to what is seen in humans with primary tauopathies and in AD. Thus, an effective tau related therapy would be expected to reduce progressive brain atrophy which is readily detectable by MRI in humans. However, there remain significant limitations in identifying the mechanisms that lead to the distinct tauopathy of AD (in humans)-i.e., the facilitation of tau aggregation and spread by $A \beta$ plaques (particularly neuritic plaques), as well as the mechanisms linking the excretion of hyperphosphorylated, soluble tau to $A \beta$ plaques. Moreover, there remain limitations in understanding the direct mechanism of toxicity of NFTs in 
humans, highlighting the need for studies in non-human models that can more easily be translated to human studies. One recent study demonstrates that, in a mouse model of amyloidosis, TREM2 expressed by microglia is able to limit amyloid-induced $\mathrm{AD}$ tau seeding and spreading as one potential mechanism tying together amyloid to tau [98]. As there are measures of soluble CSF tau in humans, preclinical models could also include similar methods of measuring TREM2 related disease progression and response to therapies. Additionally, the ultrastructural differences between AD NFTs and those of other tauopathies and how these contribute to disease onset and progression [92] all are critical considerations more amenable to preclinical mechanistic studies and could facilitate the development of more efficient prevention trials targeting tau. Table 3 outlines areas of high priority for translation of preclinical work in tauopathies to next generation prevention trials in $\mathrm{AD}$.

\section{Summary}

The association between misfolded tau and the clinical symptoms of $\mathrm{AD}$ prioritizes tau for developing treatments in $\mathrm{AD}$. Yet, the recent history of $\mathrm{A} \beta$ specific therapies illustrates the immense challenge of targeting misfolded proteins in neurodegeneration. Recent advancements in tau biomarkers, in pre-symptomatic and symptomatic $\mathrm{AD}$ has provided the opportunity for a more precise approach in preclinical models. Essential to this is the use of models that better reflect the tauopathy of $\mathrm{AD}$ and consideration of how to also adapt mechanistic studies that integrate tools and biomarkers currently available in clinical studies.

Finally, the discovery and validation of AD bloodbased biomarkers, made possible with the development of novel techniques (e.g. immunoprecipitation-mass spectrometry or the high-precision immunoassays) [23, 25, 99-101] will offer major opportunities for screening and enrollment of potential participants for primary and secondary prevention trials, reducing trial duration and costs due to screen failures.

\section{Additional targets}

\section{Therapeutic approaches targeting inflammation and microglia}

Neuroinflammation is now recognized as a prominent feature in the neurodegeneration process leading to symptomatic AD [102-106]. Microglial and astrocytic activation are thought to play a major role in the initiation and exacerbation of CNS inflammation in response to AD pathology [107, 108]. Although classical neuropathological lesions in $\mathrm{AD}$ include neuritic plaques composed of $A \beta$ and intraneuronal accumulation of NFTs

Table 3 Opportunities and Challenges of translating preclinical studies of tau

\begin{tabular}{|c|c|c|c|}
\hline Area of focus & Model & Need & Opportunity for translation \\
\hline $\begin{array}{l}\text { Conformational } \\
\text { specificity of } \\
\text { aggregated tau } \\
\text { (disease specific) }\end{array}$ & $\begin{array}{l}\text { - } \quad \text { Transgenic models/knock } \\
\text { in; } \\
\text { - iPSC/iNeuron (mutation } \\
\text { related tau/AD; non-genetic } \\
\text { disease specific (PSP/CBD)) } \\
\text { - } \quad \text { Brain organoids }\end{array}$ & $\begin{array}{l}\text { - Greater fidelity to AD: amyloid and tau co- } \\
\text { pathology } \\
\text { - } \quad \text { Specific ultrastructural conformation of AD } \\
\text { tau } \\
\text { - Better evidence of soluble tau/p-tau } \\
\text { changes (CSF/blood) }\end{array}$ & $\begin{array}{l}\text { - Expand transgenic tau (MAPT) models to } \\
\text { include mutations with evidence of AD } \\
\text { type pathology (R406W) } \\
\text { - Establish standards within the preclinical } \\
\text { field of testing tau therapeutics that } \\
\text { represent multiple conformational species } \\
\text { of tau }(\geqq 2) \text {. }\end{array}$ \\
\hline $\begin{array}{l}\text { Soluble } \\
\text { (extracellular) vs } \\
\text { aggregated tau } \\
\text { (biomarker } \\
\text { validation) }\end{array}$ & $\begin{array}{l}\text { - } \quad \text { AD transgenic models } \\
\text { (with/without tau injection } \\
\text { paradigm) } \\
\text { - } \quad \text { iPSC/iNeuron }\end{array}$ & $\begin{array}{l}\text { - Better understanding of the role of } \\
\text { extracellular tau and the various truncated p- } \\
\text { tau species (impact on neuronal function; re- } \\
\text { sponse to stressors (e.g. extracellular amyloid) } \\
\text { _ Impact of targeting specific soluble tau } \\
\text { species in AD prevention }\end{array}$ & $\begin{array}{l}\text { _ Determine extent of soluble CSF/plasma } \\
\text { tau and p-tau profiles identified in humans } \\
\text { with AD and tau transgenics } \\
\text { _ Preclinical studies targeting specific } \\
\text { kinases related to amino acid specific } \\
\text { phosphorylation } \\
\text { _ Preclinical studies targeting specific } \\
\text { soluble p-tau isoforms }\end{array}$ \\
\hline $\begin{array}{l}\text { Abeta-tau } \\
\text { interaction (AD } \\
\text { tauopathy) }\end{array}$ & $\begin{array}{l}\text { - } \quad \text { Tau injections (AD specific) } \\
\text { in } A D \text { transgenic models } \\
\text { - } \quad \text { Brain organoid } \\
\text { - iPSC/iNeuron models (AD } \\
\text { mutations) }\end{array}$ & $\begin{array}{l}\text { - AD specific models that include both } \\
\text { Amyloid and tau pathologies (preferably on } \\
\text { different APOE backgrounds) }\end{array}$ & $\begin{array}{l}\text { - Measurement of soluble tau in Amyloid } \\
\text { targeted therapies }\end{array}$ \\
\hline $\begin{array}{l}\text { Seeding propensity } \\
\text { of tau (tau strains) }\end{array}$ & $\begin{array}{l}\text { - } \quad \text { Transgenic models/knock } \\
\text { in; } \\
\text { - } \quad \text { iPSC/iNeuron (mutation } \\
\text { related tau/AD; non-genetic } \\
\text { disease specific (PSP/CBD/ } \\
\text { sporadic AD)) } \\
\text { - Brain organoids (mutation } \\
\text { related tau/AD; non-genetic } \\
\text { disease specific (PSP/CBD/ } \\
\text { sporadic AD)) }\end{array}$ & & $\begin{array}{l}\text { - } \quad \text { Use of Tau PET in preclinical studies } \\
\text { (same tracers as in clinical studies) } \\
\text { _ } \quad \text { Standardize methods for determining } \\
\text { seeding propensity of tau for consistent } \\
\text { reference across the field } \\
\text { - Include multiple AD patient tau "seeds" } \\
\text { in preclinical models that are } \\
\text { representative of various clinical features } \\
\text { (rapidly progressive vs slowly progressive) }\end{array}$ \\
\hline
\end{tabular}


featuring hyperphosphorylated tau [54, 109], numerous studies describe the presence of activated glial cells in the vicinity of the plaques. The spatial relation between $A \beta$ and reactive glial cells suggests that glial cells are activated by aggregated $A \beta$ [110], triggering an inflammatory response at the early stages of the disease (before symptomatic phases). Several AD models consider that early glial activation may be protective by facilitating $A \beta$ phagocytosis and degradation. However, the chronic inflammatory response related to glial activation may be deleterious, leading to acute neuronal membrane damage, neurotoxicity, and neurodegeneration at later stages of the disease. Moreover, microglia activation reduces the formation of neuritic dystrophy surrounding amyloid [111-113], creating a continuous cycle of molecular and cellular events that influences AD pathology progression and a neuroinflammatory response throughout the disease process. In a similar fashion, gliosis has been reported in animal models and other tauopathies in the absence of $A \beta$ pathology, suggesting a tau-dependent microglial activation that maintains the glial inflammatory response through the disease [114]. In summary, it is likely that $A \beta$ and tau synergistically contribute to neuroinflammation and neurodegeneration via chronic glial activation, but the inflammatory response has different roles at different stages of the disease.

The presence of early and chronic inflammation in $\mathrm{AD}$ via microglial activation supports the use of immunomodulating agents as potential therapies aimed at disease treatment, but the optimal timing of such intervention using such candidates is still under debate. Immunomodulating therapies might have different effects depending on the state disease; inhibition of microglial function by anti-inflammatory approaches may prove detrimental during early phases of $A \beta$ aggregation; however, it may reduce neurodegeneration during later phases of $A \beta$ aggregation and especially the NFT phases [114].

Different strategies are currently under development aimed at modulating immune cell function in neuroinflammation. Numerous studies have explored the use of non-steroidal anti-inflammatory drugs (NSAIDs); however, despite compelling evidence in animal models highlighting the protective effects of NSAIDs in AD, clinical trials using these compounds for AD treatment have been mostly disappointing, probably related to the inclusion of participants too late into the disease course and the differential effect of immunomodulation depending on disease stage as well as the lack of CNS target engagement [115-117]. As indicated by secondary analyses from the Alzheimer's Disease Anti-inflammatory Prevention Trial (ADAPT), the effect of NSAIDs may differ according to disease stage; asymptomatic individuals treated with naproxen showed reduced AD incidence, whereas those at later stages of $\mathrm{AD}$ experienced faster cognitive decline
[118, 119]. Nevertheless, it's still controversial whether NSAIDs will provide a meaningful long-term clinical benefit [120].

Other promising candidates for inflammatory response regulation include proteins involved in microglial function and inflammation (e.g., TREM2, APOE, CD33, CR1, ABCA7 and SHIP1). The recent identification of TREM2 variants as late-onset $A D$ (LOAD) genetic risk factors has prompted several studies to determine the role of TREM2 in glial regulation and inflammatory response. TREM2 seems to play a key role in microglial recruitment, phagocytosis, and clearance of $A \beta[121,122]$. Several reports AD suggest that TREM2 deficiency results in decreased microglial activation and a subsequent reduction of plaque-associated microglia, which augments local $A \beta$ toxicity and amyloid-induced neuritic dystrophy. While these studies support augmenting TREM function in the amyloid stage of preclinical $\mathrm{AD}$, other studies show that decreasing TREM2 function in tauopathy models decreases brain atrophy and synaptic loss [123, 124]. So the timing of when to target TREM2 and the therapeutic mechanism (activation or inhibition) to treat $\mathrm{AD}$ pathology remains to be determined depending on disease stage [112].

Ultimately, the successful implementation of immunomodulating therapies might lie in maintaining the fine balance between reparative and damaging functions but will almost certainly be a component of combination therapies for $\mathrm{AD}$.

\section{Therapeutic approaches targeting apolipoprotein E function}

APOE4 is the most prevalent genetic risk factor for $\mathrm{SAD}$, with several studies pointing out a strong relationship between APOE- $\varepsilon 4$ and AD pathology [125, 126]. APOE4 carriers are more likely to develop AD several years earlier relative to $A P O E 3$ and with a dose-dependent effect. Conversely, $A P O E 2$ carriers have a 'protective' effect relative to $A P O E 3$ and $A P O E 4$ carriers, most likely through both $A \beta$-dependent and other independent mechanisms yet to be determined [127]. These findings suggest a possible toxic effect of APOE- $\varepsilon 4$ in the brain, providing an avenue to delay or stop the development of $A D$ via blocking APOE- $\varepsilon 4$ expression. Current concepts for APOE-targeted AD therapies include: (1) regulation of ApoE levels; (2) modification of ApoE properties or structure; (3) re-programing APOE function via gene editing and (4) indirect therapeutic approaches via ApoE receptor modification, maintaining vasculature integrity, and inflammatory systems. More detailed information regarding APOE-targeted $\mathrm{AD}$ therapies are provided in previous reviews [128-130].

However, there are some limitations to these approaches, including: (1) The percentage of people 
with at least one APOE- $\varepsilon 4$ allele in the population is $\sim 25 \%$ and the relation between APOE4 and dementia risk varies according to population admixture [127, $131,132]$, therefore the number of individuals to benefit from this approach may be somewhat limited in a prevention platform. It should be noted, however, that $\sim 65 \%$ of people with symptomatic AD carry at least one E4 allele; (2) although APOE isoforms have been implicated in numerous processes, including crosstalk with $\mathrm{A} \beta[133,134]$, tau phosphorylation [126], lipid metabolism, vascular function [135, 136] and inflammation [137], the molecular mechanisms that mediate the pathological effects of APOE- 44 in AD development remain to be determined; (3) most animals models in $A D$ express non-physiological levels of expression of $A \beta$ and tau, thus it is difficult to assess if findings from $A P O E$ modification in these models will yield similar results in human clinical trials. Answers to these questions via better understanding of APOE modification in animal models may pave the way for a more targeted approach to APOE-based therapies in AD.

Despite our increased understanding of the detrimental effect of APOE- $\varepsilon 4$, there is also sufficient evidence of a protective effect of APOE- $\varepsilon 2$ against AD $[127,138]$; therefore, it is reasonable to consider that APOE- $\varepsilon 2$ based therapies may yield significant therapeutic effects in APOE- $\varepsilon 4$ and APOE- $\varepsilon 3$ individuals. Viral-mediated overexpression of APOE2 or converting APOE- $\varepsilon 4$ to APOE- $\varepsilon 2$ via gene-editing tools such as the CRISPR-Cas system may constitute costeffective targets for primary and secondary prevention trials in APOE- $\varepsilon 4$ and APOE- $\varepsilon 3$ individuals. However, the mechanism underlying the protective effect of APOE- $\varepsilon 2$ has remain mostly elusive and more evidence from animal models will be required before fully proceeding to prevention trials. Due to the duration of these trials, a better understanding of the long term effects of APOE- $\varepsilon 2$ overexpression is required, including for possible detrimental effects such as increased risk for stroke [139-141], CAA [142, 143] and age related macular degeneration [144, 145]. Supporting for interventions that aim to modify or edit APOE comes from the recent report that homozygosis for the APOE3 Christchurch variant (R136S) markedly delayed cognitive decline in a single presenilin 1 (PSEN1) mutation carrier [146]. However, these findings will warrant further replication in animal models before moving to therapeutic trials. Furthermore, whether the protective effect of the APOE3 Christchurch variant is through disruption of tau spread or decreasing the ability of APOE to initiate a microglial-mediated inflammatory response to tau pathology remains to be determined.

\section{Combination therapies in prevention trials}

The conceptualization of AD as a chronic illness of over 20 years duration supports these two hypotheses: (1) mechanism-based therapies for $\mathrm{AD}$ will have optimal benefit when initiated in the asymptomatic stage, prior to substantial damage to synapses and neurons (see previous sections); and (2) once the $\mathrm{AD}$ pathological cascade has been initiated, a combination of therapies that together target multiple aspects of AD pathology will be more effective than monotherapies that address only a single abnormal factor (e.g., the cerebral accumulation of aggregated $A \beta)$. Although the complex biological mechanisms leading to $\mathrm{AD}$ (e.g., $\mathrm{A} \beta$ plaques, NFTs, and inflammation) suggest that the disease may be more effectively treated with a combination approach rather than a single therapy, to date most AD trials have evaluated a putative disease-modifying monotherapy (without success). Thus, there is a need for new and more innovative study designs, including the implementation of combination trials. The issues pertinent to combination therapy in $\mathrm{AD}$ are comparable to combination therapies that are used in other chronic illnesses such as cancer and cardiovascular disease.

A Cochrane review of five trials in individuals with symptomatic AD with a range of Mini Mental State Examination [147] scores from 5 to 22 found a small but significant benefit of the combination of an approved cholinesterase inhibitor and memantine for global, cognitive, and behavioral measures but no benefit for instrumental and basic activities of daily living [148]. Hence, combination therapy with "standard of care" medications provides at best an uncertain clinical benefit [148]. Greater efficacy may be realized with combinations of mechanism-based therapies. Combination therapies can be evaluated with an add-on trial design, where the effects of a new therapy are compared with placebo on the background of a known effective therapy for AD. Because no anti-AD therapy has yet demonstrated efficacy, the focus here will be on combination therapies that feature a $2 \times 2$ factorial trial design, in which each of 2 drugs (addressing different targets) are tested alone and in combination versus placebo [149].

A $\beta$ remains an important target [150] for diseasemodifying therapies in $\mathrm{AD}$, although to date, clinical trials of anti- $A \beta$ monotherapies in persons with symptomatic $\mathrm{AD}$ have failed to clearly demonstrate clinical efficacy. However, on the basis of removing amyloid plaques, the US FDA recently gave accelerated approval of aducanumab, thus further enabling combination treatments to include a treatment to remove amyloid plaques. A combination therapy for $\mathrm{AD}$ might address different points in the pathway leading to deposits of aggregated $A \beta-42$, such as a monoclonal antibody directed toward $A \beta-42$ and a $\beta$-secretase ( $\beta$-site 
APP cleaving enzyme 1, or BACE) inhibitor to both remove deposited amyloid via the antibody and reduce the generation of new amyloidogenic isoforms with the BACE inhibitor. Unexpected cognitive worsening, as well as other potential adverse effects (e.g., hepatotoxicity, weight loss or neuropsychiatric symptoms), with BACE inhibitors in phase $2 / 3$ trials have halted their therapeutic development in $\mathrm{AD}[11,12,151]$, but the model targeting the amyloid pathway at different stages remains a viable strategy, and may be facilitated by next generation gamma secretase modulators [152, 153]. Another approach to combination therapy is to target two (or more) pathogenic pathways. Anti-tau agents already are in clinical trial, leading to consideration of combining anti-amyloid and anti-tau therapies [154]. Other potential combinations of therapies that have diverse mechanisms of action could include agents that address neuroinflammation, apolipoprotein E, mitochondrial modifiers, free radicals, autophagy, or the disrupted blood-brain barrier $[44,155]$. In addition, future studies should explore the potential role of human induced pluripotent stem cells (hiPSCs) in AD treatment, however to improve the interpretation of hiPSC experiments, more effective animal models and access to primary or age-matched cells from the human CNS are needed (Table 3).

Current trials should take into consideration the significant evidence of multiple pathologies co-occurring with $\mathrm{AD}$, including vascular brain injury, cerebral amyloid angiopathy (CAA), Lewy body pathology and TDP-43 inclusions [156-158]. Presence of AD co-pathologies may influence neurodegeneration, lowering the threshold and contribute to faster cognitive decline; which further supports the relevance of combinations therapies aimed to slow cognitive decline. Therapeutic interventions should also be coupled with lifestyle interventions to reduce dementia risk. As shown by the Finnish Geriatric Intervention Study to Prevent Cognitive Impairment and Disability (FINGER) study, multidomain lifestyle intervention (e.g., physical exercise, a healthy diet, cognitive stimulation) could improve or maintain cognitive functioning in at-risk elderly individuals [159]. Similar to the FINGER study, the US study to Protect Brain Health Through Lifestyle Intervention to Reduce Risk (US-POINTER), will test whether a similar 2-year intensive lifestyle intervention, adapted to American culture, can protect cognitive function in older adults in the U.S. [160] Several global initiatives are under way, under the World-Wide FINGERS Network aimed to determine whether lifestyle interventions that simultaneously target many risk factors protect cognitive function in older adults who are at increased risk for cognitive decline [160, 161]. Related to studies of lifestyle interventions, similar rigor of non-human, mechanistic studies should also be applied to better understand the mechanisms of potential clinical benefits of exercise, diet and cognitive stimulation. Finally, as we advanced in AD therapeutic strategies, clinical trials should enroll and follow participants from all ethnic and racial groups so that the results are applicable to all.

Determining which mechanisms to target will depend on multiple factors, including the availability of appropriate drugs with preclinical evidence of efficacious target engagement and an acceptable safety profile, the stage of $\mathrm{AD}$ (preclinical or symptomatic), and potentially a precision medicine approach to identify individual mechanistic pathways that then would determine a specific combination of drugs to target relevant pathways [44].

The use of combination therapies has already proven to be successful in complex diseases like rheumatoid arthritis, cancer, tuberculosis, and HIV/AIDS, and are also likely to increase the odds for success in AD therapy development. However, the roadmap for combination therapies in $\mathrm{AD}$ will require addressing several challenges including: (1) lack of predictable animal models to test multiple targets (e.g., newer $\mathrm{AD}$ animal models will be required to express multiple disease mechanisms), (2) determination of which pathways to target based on disease stage (e.g., ideally, each drug in a combination therapy must target distinct disease pathways and be stage-specific, such as having one drug target $A \beta$ plaque removal and another prevent tau tangle formation in early stages of the disease) (3) how to handle complex clinical trial designs to determine additive versus synergistic treatment effects of two or more novel therapies, and (4) addressing safety concerns about additive toxicity from drugs administered simultaneously. Finally, although there are many as yet unresolved issues to address, including timing of the intervention, duration of therapy, and adverse events of the therapeutic agents, trials of combination therapies should be developed not only to evaluate efficacy in persons with symptomatic $\mathrm{AD}$ but also for secondary prevention in cognitively normal individuals with biomarker evidence of preclinical AD. It is possible to use molecular biomarkers to "stage" preclinical $\mathrm{AD}$ and identify individuals who are most at risk of developing symptomatic $\mathrm{AD}$ within a defined observation period [162]; new biomarkers may further inform that risk [68].

Prevention trials of combination therapies may offer greater chances of benefit, in either delaying or even preventing the onset of symptomatic $\mathrm{AD}$, than trying to reverse or halt cognitive and functional decline in individuals who already have symptomatic $\mathrm{AD}$ and thus have experienced irreversible cerebral damage.

\section{Conclusions}

$\mathrm{AD}$ prevention trials have the potential and promise to achieve highly successful therapeutic goals of delaying or 
Table 4 Basic and Translational recommendations to advance AD prevention trials

\begin{tabular}{ll}
\hline 1) Target validation & Demonstrate necessary or sufficient factors for developing AD pathology and disease (e.g. ApoE, TREM2, \\
& mutations in PSEN1, PSEN2, APP) \\
& Discover human variations that negate risk for AD (e.g. Icelandic and ApoE mutations) \\
& Determine the atomic models of AD pathology for amyloid plaques and other associated pathologies (e.g. \\
& synapse and neuron loss, alpha-synuclein, TDP-43) as has been accomplished for tau tangles. \\
& ldentify the relationships between biological changes and consequences of amyloid, tau, and \\
& neurodegeneration changes as it relates to $A D$ and clinical manifestation. \\
& Diversified testing of tau targets and mechanisms are essential to addressing target validation.
\end{tabular}

2) Animal and in vitro model development

3) Biomarker development

4) Prevention trial design
Simulate and model the different forms of tauopathies (AD vs. 4R tauopathies) to emulate the molecular and structural pathology present in each disease. Both in vitro and animal in vivo preclinical model studies need to match the disease to inform clinical trial design.

Simulate and model $A \beta$ amyloid plaque and other isoform changes with human AD stages. Implement standardization protocols for testing $A \beta$ therapies by stage of disease to include primary prevention (pre-plaque), secondary prevention (plaque growth stage before tangles), symptomatic (fully established amyloid plaque load with downstream consequences in tau aggregation and neurodegeneration) in transgenic or other related in vivo models.

Create greater fidelity of AD in animal models: amyloid and tau co-pathology; specific ultrastructural conformation of $\mathrm{AD}$ tau and better recapitulate the sequence of stages, for example, soluble tau and $\mathrm{p}$-tau changes in CSF and blood.

Develop models of AD inflammation and microglial activity that mimics the specific $A D$ related inflammation and neurodegeneration.

Develop standard assays and techniques to measure drug effects on pathology, pharmacodynamics, and pharmacokinetics in animal and cellular models that are most directly translatable to human clinical studies. Accelerate studies and programs of preclinical models that can test rational combinations with a focus on translating these to prevention trials. For example, removing amyloid while preventing the spread of tau pathology.

Develop novel biomarkers that can track pre-clinical biological changes and distinguish stages of pre-clinical AD and predict future biological and clinical changes.

Understand the relationship between currently available biomarkers and the pathophysiology of the AD process and how this relates to pathology and current and future clinical measures. For example, how do different phosphorylated tau species related to tau aggregation in the brain and to clinical onset and progression? Improve understanding of biomarkers relation to clinical symptoms and age at onset. For example, track the longitudinal changes in amyloid-beta, soluble tau species vs. aggregated tau changes

Improve prevention trial screening accuracy through the development and implementation of cost-effective non-invasive biomarkers. What combination of biomarkers are optimal for identifying stage of disease, years to clinical onset and decline and prognostic of rates of decline?

Identify stages of asymptomatic disease that match the pathophysiology with the intervention target. For example, intervening in tau spread during rapid tau aggregation growth, or blocking the amyloid-tau link before tau pathology becomes autonomous.

Develop sensitive cognitive measures aimed at demonstrating efficacy in the very earliest detectable stages of AD. Novel approaches may need to include rapid and frequent sampling and significantly complex cognitive tasks to accurately track asymptomatic cognitive dysfunction. preventing $\mathrm{AD}$ dementia. The impact of preserving cognitive independence is enormous and justifies the currently challenging and uncertain initial prevention efforts. Basic and Translational recommendations to advance $\mathrm{AD}$ prevention are shown in Table 4. AD prevention challenges that must be met are defining optimal targets, when and what asymptomatic stage to target the different pathologies, developing relevant $\mathrm{AD}$ prevention model studies that inform clinical prevention strategies, and the informed design of combination interventions for this complex neurodegenerative disorder. These are all attainable aims that require the investment of basic, translational and clinical researchers working together with the common goal of maximally informing clinical prevention efforts. Although developing prevention approaches can be challenging, the substantial long-term benefits of cholesterol-lowering statins in individuals at high risk of cardiovascular disease provides an instructive lesson about prevention which can be replicated in AD. The approach is being taken in AD by defining targets based on necessary and sufficient conditions to cause disease (increased cholesterol/atherosclerosis vs. amyloid/tau aggregation), and then treating with interventions that have large impacts on the target, at a stage of disease before downstream or endorgan damage occurs. As a field, if we are successful in this prevention approach, years to decades of independent living may be provided to millions of at-risk people.

\section{Abbreviations}

AAV: Adeno-associated virus; AD: Alzheimer's disease; ALS: Amyotrophic lateral sclerosis; ApoE: Apolipoprotein E; APP: Amyloid precursor protein; ASOs: Antisense oligonucleotides; A $\beta$ : Amyloid- $\beta$ peptide; BACE: $\beta$-Site amyloid precursor protein cleaving enzyme; CNS: Central nervous system; CRISPR: Clustered regularly interspaced short palindromic repeats; CSF: Cerebral spinal fluid; DIAN-TU: Dominant Inherited Alzheimer Network Trials Units; FTLD: Frontotemporal lobar dementia; GSI: $\gamma$-Secretase inhibitors; hiPSCs: Human induced pluripotent stem cells; LOAD: Late-onset Alzheimer 
disease; MAPT: Microtubule associated protein tau; NFTs: Neurofibrillary tangles; NSAIDs: Non-steroidal anti-inflammatory drugs; PSEN: Presenilin; SAD: Sporadic Alzheimer disease; siRNA: Small interfering RNA;

TREM: Triggering receptors expressed on myeloid cells

\section{Acknowledgments}

We acknowledge the altruism of the research participants and their families and contributions of the research scientists and support staff for their contributions.

\section{Funding/support}

This review was supported by grants from the National Institute on Aging of the National Institutes of Health under Award Numbers U01AG042791, R1AG046179, R01/R56 AG053267, U01AG059798. The content is solely the responsibility of the authors and does not necessarily represent the official views of the National Institutes of Health.

\section{Role of the funder/sponsor}

The funding source had no role in the design and conduct of the study; collection, management, analysis, and interpretation of the data; preparation, review, or approval of the manuscript; and decision to submit the manuscript for publication.

\section{Authors' contributions}

EM, JLG, DH, JM and RJB wrote the article, provided critical feedback and revised the manuscript. All authors read and approved the final manuscript.

\section{Availability of data and materials}

Not applicable.

\section{Declarations}

\section{Ethics approval and consent to participate}

Not applicable.

\section{Consent for publication}

Not applicable.

\section{Competing interests}

Dr. McDade, is the Associate Director of the DIAN-TU. He reports serving on a Data Safety Committee for Eli Lilly and Company and Alector; scientific consultant for Eisai and Eli Lilly and Company; institutional grant support from Eli Lilly and Company, F. Hoffmann-La Roche, Ltd. and Janssen. Dr. Morris, is the Friedman Distinguished Professor of Neurology, Director, Knight ADRC; Associate Director of DIAN and Founding Principal Investigator of DIAN. He is funded by NIH grants \# P30 AG066444; P01AG003991; P01AG026276; U19 AG032438; and U19 AG024904. Neither Dr. Morris nor his family owns stock or has equity interest (outside of mutual funds or other externally directed accounts) in any pharmaceutical or biotechnology company. Dr. Holtzman, is the Department Head of Neurology where the research is being conducted, is an inventor on patents for solanezumab, currently being tested in the DIAN-TU clinical trials. If solanezumab is approved as a treatment for Alzheimer's disease or dominantly inherited Alzheimer's disease, Washington University and Dr. Holtzman will receive part of the net sales of solanezumab from Eli Lilly and Company, which has licensed patents related to solanezumab from Washington University. Dr. Bateman, is the Director of the DIAN-TU and Principal Investigator of the DIAN-TU-001. He receives research support from the National Institute on Aging of the National Institutes of Health, DIAN-TU Trial Pharmaceutical Partners (Eli Lilly and Company, F. Hoffman-La Roche, Ltd., and Avid Radiopharmaceuticals), Alzheimer's Association, GHR Foundation, Anonymous Organization, DIAN-TU Pharma Consortium (Active: Biogen, Eisai, Eli Lilly and Company, Janssen, F. Hoffmann-La Roche, Ltd./Genentech. Previous: AbbVie, Amgen, AstraZeneca, Elan, Forum, Mithridion, Novartis, Pfizer, Sanofi, United Neuroscience). He has been an invited speaker, advisory board member and consultant for F. Hoffman La Roche, Ltd., an invited speaker and consultant for AC Immune and Janssen and a consultant for Amgen and Eisai. Dr. Llibre-Guerra, reports no conflict of interest relevant to this manuscript.

\section{Author details}

'Department of Neurology, Washington University in St Louis, 660 S. Euclid Avenue, Campus Box, St Louis, MO 8111, USA. Knight Alzheimer's Disease Research Center, Washington University School of Medicine, St. Louis, MO 63110, USA. ${ }^{3}$ Dominantly Inherited Alzheimer's Network Trials Unit, St. Louis, MO 63110, USA

Received: 19 February 2021 Accepted: 10 June 2021

Published online: 21 July 2021

\section{References}

1. Barnes DE, Yaffe K. The projected effect of risk factor reduction on Alzheimer's disease prevalence. Lancet Neurol. 2011;10:819-28.

2. Cummings J, Aisen PS, DuBois B, Frölich L, Jack CR, Jones RW, et al. Drug development in Alzheimer's disease: the path to 2025. Alzheimers Res Ther. 2016;8:39. https://doi.org/10.1186/s13195-016-0207-9.

3. Livingston G, Huntley J, Sommerlad A, Ames D, Ballard C, Banerjee S, et al. Dementia prevention, intervention, and care: 2020 report of the Lancet Commission. Lancet. 2020; https://doi.org/10.1016/S0140-6736(20)30367-6.

4. Zissimopoulos J, Crimmins E, St. Clair P. The value of delaying Alzheimer's disease onset. Forum Health Econ Policy. 2015;18:25-39. https://doi.org/10.1 515/fhep-2014-0013.

5. 2016 Alzheimer's disease facts and figures. Alzheimers Dement. 2016;12 459-509. https://doi.org/10.1016/J.JALZ.2016.03.001.

6. Morris JC, Blennow K, Froelich L, Nordberg A, Soininen H, Waldemar G, et al. Harmonized diagnostic criteria for Alzheimer's disease: recommendations. J Intern Med. 2014;275:204-13. https://doi.org/10.1111/joim.12199.

7. Ricciarelli R, Fedele E. The amyloid cascade hypothesis in Alzheimer's disease: it's time to change our mind. Curr Neuropharmacol. 2017;15:926. https://doi.org/10.2174/1570159x15666170116143743.

8. Bateman RJ, Xiong C, Benzinger TLS, Fagan AM, Goate A, Fox NC, et al. Clinical and biomarker changes in dominantly inherited Alzheimer's disease. N Engl J Med. 2012;367:795-804. https://doi.org/10.1056/NEJMoa1202753.

9. Jack CR, Knopman DS, Jagust WJ, Shaw LM, Aisen PS, Weiner MW, et al. Hypothetical model of dynamic biomarkers of the Alzheimer's pathological cascade. Lancet Neurol. 2010;9:119-28.

10. Doody RS, Raman R, Farlow M, Iwatsubo T, Vellas B, Joffe $S$, et al. A phase 3 trial of semagacestat for treatment of Alzheimer's disease. N Engl J Med. 2013:369:341-50. https://doi.org/10.1056/NEJMoa1210951.

11. Egan MF, Kost J, Voss T, Mukai Y, Aisen PS, Cummings JL, et al. Randomized trial of verubecestat for prodromal Alzheimer's disease. N Engl J Med. 2019; 380:1408-20. https://doi.org/10.1056/NEJMoa1812840.

12. Egan MF, Kost J, Tariot PN, Aisen PS, Cummings JL, Vellas B, et al. Randomized trial of verubecestat for mild-to-moderate Alzheimer's disease. N Engl J Med. 2018;378:1691-703. https://doi.org/10.1056/NEJMoa1706441.

13. Henley D, Raghavan N, Sperling R, Aisen P, Raman R, Romano G. Preliminary results of a trial of atabecestat in preclinical Alzheimer's disease. N Engl J Med. 2019;380:1483-5. https://doi.org/10.1056/NEJMc1813435.

14. Doody RS, Thomas RG, Farlow M, Iwatsubo T, Vellas B, Joffe S, et al. Phase 3 trials of solanezumab for mild-to-moderate Alzheimer's disease. N Engl J Med. 2014;370:311-21. https://doi.org/10.1056/NEJMoa1312889.

15. Honig LS, Vellas B, Woodward M, Boada M, Bullock R, Borrie M, et al. Trial of solanezumab for mild dementia due to Alzheimer's disease. N Engl J Med. 2018:378:321-30. https://doi.org/10.1056/NEJMoa1705971.

16. Sevigny J, Chiao P, Bussière T, Weinreb PH, Williams L, Maier M, et al. The antibody aducanumab reduces $A \beta$ plaques in Alzheimer's disease. Nature. 2016;537:50-6. https://doi.org/10.1038/nature19323.

17. Cummings J, Lee G, Ritter A, Sabbagh M, Zhong K. Alzheimer's disease drug development pipeline: 2019. Alzheimer's Dement Transl Res Clin Interv. 2019;5:272-93.

18. Berry SM, Connor JT, Lewis RJ. The Platform Trial. JAMA. 2015;313:1619. https://doi.org/10.1001/jama.2015.2316.

19. Bateman RJ, Aisen PS, De Strooper B, Fox NC, Lemere CA, Ringman JM, et al. Autosomal-dominant Alzheimer's disease: a review and proposal for the prevention of Alzheimer's disease. Alzheimers Res Ther. 2010;3:1. https:// doi.org/10.1186/alzrt59.

20. Jack CR, Bennett DA, Blennow K, Carrillo MC, Dunn B, Haeberlein SB, et al. NIA-AA Research Framework: toward a biological definition of Alzheimer's disease. Alzheimers Dement. 2018;14:535-62. https://doi.org/10.1016/j.jalz.2 018.02.018. 
21. Janelidze S, Mattsson N, Palmqvist S, Smith R, Beach Homas G, Serrano GE, et al. Plasma P-tau181 in Alzheimer's disease: relationship to other biomarkers, differential diagnosis, and longitudinal progression to Alzheimer's dementia. Nat Med. 2020;26:379-86. https://doi.org/10.1038/s41 591-020-0755-1.

22. Schindler SE, Bollinger JG, Ovod V, Mawuenyega KG, Li Y, Gordon BA, et al. High-precision plasma $\beta$-amyloid 42/40 predicts current and future brain amyloidosis. Neurology. 2019;93:E1647-59. https://doi.org/10.1212/WNL. 0000000000008081.

23. Barthélemy NR, Horie K, Sato C, Bateman RJ. Blood plasma phosphorylated-tau isoforms track CNS change in Alzheimer's disease. J Exp Med. 2020;16:521.

24. Schindler SE, Li Y, Todd KW, Herries EM, Henson RL, Gray JD, et al. Emerging cerebrospinal fluid biomarkers in autosomal dominant Alzheimer's disease. Alzheimer's Dement. 2019;15(5):655-65.

25. Ovod V, Ramsey KN, Mawuenyega KG, Bollinger JG, Hicks T, Schneider T, et al. Amyloid $\beta$ concentrations and stable isotope labeling kinetics of human plasma specific to central nervous system amyloidosis. Alzheimers Dement. 2017;13:841-9. https://doi.org/10.1016/j.jalz.2017.06.2266.

26. Korczyn AD. The amyloid cascade hypothesis. Alzheimers Dement. 2008;4: 176-8. https://doi.org/10.1016/j.jalz.2007.11.008.

27. Potter R, Patterson BW, Elbert DL, Ovod V, Kasten T, Sigurdson W, et al. Increased in vivo amyloid-b42 production, exchange, and loss in presenilin mutation carriers. Sci Transl Med. 2013;5:189ra77. https://doi.org/10.1126/ scitranslmed.3005615.

28. Patterson BW, Elbert DL, Mawuenyega KG, Kasten T, Ovod V, Ma S, et al. Age and amyloid effects on human central nervous system amyloid-beta kinetics. Ann Neurol. 2015;78:439-53. https://doi.org/10.1002/ana.24454.

29. Guo T, Zhang D, Zeng Y, Huang TY, Xu H, Zhao Y. Molecular and cellular mechanisms underlying the pathogenesis of Alzheimer's disease. Mol Neurodegener. 2020;15:40. https://doi.org/10.1186/s13024-020-00391-7.

30. Mattson MP. Secreted forms of $\beta$-amyloid precursor protein modulate dendrite outgrowth and calcium responses to glutamate in cultured embryonic hippocampal neurons. J Neurobiol. 1994;25:439-50. https://doi. org/10.1002/neu.480250409.

31. Rhein V, Eckert A. Effects of Alzheimer's amyloid-beta and tau protein on mitochondrial function - role of glucose metabolism and insulin signalling. Arch Physiol Biochem. 2007;113:131-41. https://doi.org/10.1080/138134 50701572288

32. de Jesus RV, Guimarães FM, Diniz BS, Forlenza OV. Neurobiological pathways to Alzheimer's disease: amyloid-beta, TAU protein or both? Dement Neuropsychol. 2009;3:188-94. https://doi.org/10.1590/s1980-57642 009dn30300003.

33. Gilman S, Koller M, Black RS, Jenkins L, Griffith SG, Fox NC, et al. Clinical effects of $A \beta$ immunization (AN1792) in patients with $A D$ in an interrupted trial. Neurology. 2005;64:1553-62. https://doi.org/10.1212/01.WNL.000015974 0.16984.3C.

34. Farlow MR, Andreasen N, Riviere ME, Vostiar I, Vitaliti A, Sovago J, et al. Long-term treatment with active $A \beta$ immunotherapy with CAD106 in mild Alzheimer's disease. Alzheimers Res Ther. 2015;7:1-13. https://doi.org/10.11 86/s13195-015-0108-3.

35. Pasquier $F$, Sadowsky $C$, Holstein A, Leterme GLP, Peng $Y$, Jackson $N$, et al, Two phase 2 multiple ascending-dose studies of vanutide cridificar (ACC001) and QS-21 adjuvant in mild-to-moderate Alzheimer's disease. J Alzheimers Dis. 2016;51:1131-43. https://doi.org/10.3233/JAD-150376.

36. Salloway S, Sperling R, Fox NC, Blennow K, Klunk W, Raskind M, et al. Two phase 3 trials of Bapineuzumab in mild-to-moderate Alzheimer's disease. N Engl J Med. 2014;370:322-33. https://doi.org/10.1056/NEJMoa1304839.

37. Farlow M, Arnold SE, Van Dyck CH, Aisen PS, Snider BJ, Porsteinsson AP, et al. Safety and biomarker effects of solanezumab in patients with Alzheimer's disease. Alzheimers Dement. 2012;8:261-71. https://doi.org/10.1 016/j.jalz.2011.09.224

38. Barão S, Moechars D, Lichtenthaler SF, De Strooper B. BACE1 physiological functions may limit its use as therapeutic target for Alzheimer's disease. Trends Neurosci. 2016:39:158-69. https://doi.org/10.1016/j.tins.2016.01.003.

39. Doody RS, Raman R, Sperling RA, Seimers E, Sethuraman G, Mohs R, et al. Peripheral and central effects of $\gamma$-secretase inhibition by semagacestat in Alzheimer's disease. Alzheimers Res Ther. 2015;7:36. https://doi.org/10.1186/ s13195-015-0121-6.

40. Karran E, De Strooper B. The amyloid cascade hypothesis: are we poised for success or failure? J Neurochem. 2016;139:237-52. https://doi.org/10.1111/ jnc.13632.
41. Karran E, Mercken M, De Strooper B. The amyloid cascade hypothesis for Alzheimer's disease: an appraisal for the development of therapeutics. Nat Rev Drug Discov. 2011;10:698-712.

42. Cummings JL, Morstorf T, Zhong K. Alzheimer's disease drug-development pipeline: few candidates, frequent failures. Alzheimers Res Ther. 2014;6:37. https://doi.org/10.1186/alzrt269.

43. Salloway S, Farlow M, McDade E, et al. A trial of gantenerumab or solanezumab in dominantly inherited Alzheimer's disease. Nat Med (2021). https://doi.org/10.1038/s41591-021-01369-8.

44. Lacosta AM, Pascual-Lucas M, Pesini $P$, et al. Safety, tolerability and immunogenicity of an active anti-A $\beta(40)$ vaccine (ABvac40) in patients with Alzheimer's disease: a randomised, double-blind, placebo-controlled, phase trial. Alzheimers Res Ther. 2018;10(1):12. https://doi.org/10.1186/s13195-0180340-8.

45. Scheltens $P$, Hallikainen M, Grimmer T, Duning T, Gouw AA, Teunissen CE, et al. Safety, tolerability and efficacy of the glutaminyl cyclase inhibitor PQ912 in Alzheimer's disease: results of a randomized, double-blind, placebo-controlled phase 2a study. Alzheimers Res Ther. 2018;10:107. https://doi.org/10.1186/s13195-018-0431-6.

46. Golde TE. Overcoming translational barriers impeding development of Alzheimer's disease modifying therapies. J Neurochem. 2016;139:224-36.

47. Oddo S, Caccamo A, Shepherd JD, Murphy MP, Golde TE, Kayed R, et al. Triple-transgenic model of Alzheimer's Disease with plaques and tangles: intracellular $A \beta$ and synaptic dysfunction. Neuron. 2003;39:409-21. https:// doi.org/10.1016/S0896-6273(03)00434-3.

48. Colton CA, Wilcock DM, Wink DA, Davis J, Van Nostrand WE, Vitek MP. The effects of NOS2 gene deletion on mice expressing mutated human ABPP. J Alzheimers Dis. 2008;15:571-87. https://doi.org/10.3233/JAD-2008-15405.

49. Brendel M, Jaworska A, Herms J, Trambauer J, Rötzer C, Gildehaus F-J, et al. Monitoring of chronic $\gamma$-secretase modulator treatment by serial amyloidPET. Mol Psychiatry. 2015;20:1141.

50. Strobel G. In DIAN-TU, Gantenerumab Brings Down Tau. By a Lot. Open Extension Planned. Alzforum; 2020.

51. Bowman Rogers M. Exposure, exposure, exposure? At CTAD, Aducanumab Scientists Make a Case. Alzforum; 2019.

52. Bateman RJ, Ryan LM, Carrillo MC, Kerchner GA, Farlow MR, Salloway SP et al. Panel Discussion: DIAN-TU Trial Collaborative Effort. 2020. https://alz. confex.com/alz/20amsterdam/meetingapp.cgi/Paper/41133. Accessed 13 Nov 2020.

53. Braak H, Braak E. Staging of Alzheimer's disease-related neurofibrillary changes. Neurobiol Aging. 1995;16:271-8.

54. Braak H, Thal DR, Ghebremedhin E, Del Tredici K. Stages of the pathologic process in Alzheimer disease: age categories from 1 to 100 years. J Neuropathol Exp Neurol. 2011;70:960-9. https://doi.org/10.1097/NEN.0b013 e318232a379.

55. Arriagada PV, Growdon JH, Hedley-Whyte ET, Hyman BT. Neurofibrillary tangles but not senile plaques parallel duration and severity of Alzheimer's disease. Neurology. 1992;42:631-9. https://doi.org/10.1212/wnl.42.3.631.

56. Nelson PT, Alafuzoff I, Bigio EH, Bouras C, Braak H, Cairns NJ, et al. Correlation of Alzheimer disease neuropathologic changes with cognitive status: a review of the literature. J Neuropathol Exp Neurol. 2012;71:362-81. https://doi.org/10.1097/NEN.0b013e31825018f7.

57. Ossenkoppele R, Schonhaut DR, Schöll M, Lockhart SN, Ayakta N, Baker SL, et al. Tau PET patterns mirror clinical and neuroanatomical variability in Alzheimer's disease. Brain. 2016;139:1551-67. https://doi.org/10.1093/brain/a ww027.

58. Janelidze S, Stomrud E, Smith R, Palmqvist S, Mattsson N, Airey DC, et al. Cerebrospinal fluid p-tau217 performs better than p-tau181 as a biomarker of Alzheimer's disease. Nat Commun. 2020;11(1):1683.

59. Barthélemy NR, Li Y, Joseph-Mathurin N, Gordon BA, Hassenstab J, Benzinger TLS, et al. A soluble phosphorylated tau signature links tau, amyloid and the evolution of stages of dominantly inherited Alzheimer's disease. Nat Med. 2020;26:398-407. https://doi.org/10.1038/s41591-0200781-z.

60. Nisbet RM, Polanco JC, Ittner LM, Götz J. Tau aggregation and its interplay with amyloid-ß. Acta Neuropathol. 2015;129:207-20. https://doi.org/10.1007/ s00401-014-1371-2.

61. Thijssen EH, La Joie R, Wolf A, Strom A, Wang P, laccarino L, et al. Diagnostic value of plasma phosphorylated tau181 in Alzheimer's disease and frontotemporal lobar degeneration. Nat Med. 2020;26:387-97. https://doi. org/10.1038/s41591-020-0762-2. 
62. Palmqvist S, Janelidze S, Quiroz YT, Zetterberg H, Lopera F, Stomrud E, et al. Discriminative accuracy of plasma phospho-tau217 for Alzheimer disease vs other neurodegenerative disorders. JAMA. 2020;324:772-81. https://doi. org/10.1001/jama.2020.12134

63. Bateman RJ, Barthélemy NR, Horie K. Another step forward in blood-based diagnostics for Alzheimer's disease. Nat Med. 2020;26:314-6. https://doi. org/10.1038/s41591-020-0797-4

64. Wang Y, Mandelkow E. Tau in physiology and pathology. Nat Rev Neurosci. 2016;17:22-35

65. Roberson ED. Mouse models of frontotemporal dementia. Ann Neurol. 2012;72:837-49. https://doi.org/10.1002/ana.23722.

66. Rosenmann H, Grigoriadis N, Eldar-Levy H, Avital A, Rozenstein L, Touloum $\mathrm{O}$, et al. A novel transgenic mouse expressing double mutant tau driven by its natural promoter exhibits tauopathy characteristics. Exp Neurol. 2008;212: 71-84. https://doi.org/10.1016/j.expneurol.2008.03.007.

67. Barthélemy NR, Mallipeddi N, Moiseyev P, Sato C, Bateman RJ. Tau phosphorylation rates measured by mass spectrometry differ in the intracellular brain vs. extracellular cerebrospinal fluid compartments and are differentially affected by Alzheimer's disease. Front Aging Neurosci. 2019;11:121.

68. Barthélemy NR, Bateman RJ, Hirtz C, Marin P, Becher F, Sato C, et al. Cerebrospinal fluid phospho-tau T217 outperforms T181 as a biomarker for the differential diagnosis of Alzheimer's disease and PET amyloid-positive patient identification. Alzheimers Res Ther. 2020;12:26. https://doi.org/10.11 86/s13195-020-00596-4.

69. Medina M. An overview on the clinical development of Tau-based therapeutics. Int J Mol Sci. 2018;19:1160.

70. Zhang B, Carroll J, Trojanowski JQ, Yao Y, Iba M, Potuzak JS, et al. The microtubule-stabilizing agent, epothilone $\mathrm{D}$, reduces axonal dysfunction, neurotoxicity, cognitive deficits, and Alzheimer-like pathology in an interventional study with aged tau transgenic mice. J Neurosci. 2012;32: 3601-11.

71. Tsai RM, Miller Z, Koestler M, Rojas JC, Ljubenkov PA, Rosen HJ, et al. Reactions to multiple ascending doses of the microtubule stabilizer TPI-287 in patients with Alzheimer disease, progressive supranuclear palsy, and corticobasal syndrome: a randomized clinical trial. JAMA Neurol. 2020;77: 215-24. https://doi.org/10.1001/jamaneurol.2019.3812.

72. Wagner J, Krauss S, Shi S, Ryazanov S, Steffen J, Miklitz C, et al. Reducing tau aggregates with anle138b delays disease progression in a mouse model of tauopathies. Acta Neuropathol. 2015;130:619-31.

73. Brendel M, Deussing M, Blume T, Kaiser L, Probst F, Overhoff F, et al. Latestage Anle138b treatment ameliorates tau pathology and metabolic decline in a mouse model of human Alzheimer's disease tau. Alzheimers Res Ther. 2019;11:67. https://doi.org/10.1186/s13195-019-0522-z.

74. Crowe A, James MJ, Lee VM-Y, Smith AB III, Trojanowski JQ, Ballatore C, et al. Aminothienopyridazines and methylene blue affect Tau fibrillization via cysteine oxidation. J Biol Chem. 2013;288:11024-37.

75. Forlenza OV, Radanovic M, Talib LL, Gattaz WF. Clinical and biological effects of long-term lithium treatment in older adults with amnestic mild cognitive impairment: randomised clinical trial. Br J Psychiatry. 2019;215:668-74. https://doi.org/10.1192/bjp.2019.76.

76. Spillantini MG, Goedert M. Tau pathology and neurodegeneration. Lancet Neurol. 2013;12:609-22. https://doi.org/10.1016/S1474-4422(13)70090-5.

77. Neil EE, Bisaccia EK. Nusinersen: a novel antisense oligonucleotide for the treatment of spinal muscular atrophy. J Pediatr Pharmacol Ther. 2019;24: 194-203. https://doi.org/10.5863/1551-6776-24.3.194.

78. Keil JM, Seo J, Howell MD, Hsu WH, Singh RN, DiDonato CJ. A short antisense oligonucleotide ameliorates symptoms of severe mouse models of spinal muscular atrophy. Mol Ther Nucleic Acids. 2014;3:e174.

79. Parente V, Corti S. Advances in spinal muscular atrophy therapeutics. Ther Adv Neurol Disord. 2018;11:1756285618754501. https://doi.org/10.1177/1 756285618754501

80. Schoch KM, Miller TM. Antisense oligonucleotides: translation from mouse models to human neurodegenerative diseases. Neuron. 2017:94:1056-70. https://doi.org/10.1016/j.neuron.2017.04.010.

81. DeVos SL, Miller RL, Schoch KM, Holmes BB, Kebodeaux CS, Wegener AJ, et al. Tau reduction prevents neuronal loss and reverses pathological tau deposition and seeding in mice with tauopathy. Sci Transl Med. 2017;9: eaag0481. https://doi.org/10.1126/scitranslmed.aag0481.

82. Hutton M, Lendon CL, Rizzu P, Baker M, Froelich S, Houlden HH, et al. Association of missense and 5'-splice-site mutations in tau with the inherited dementia FTDP-17. Nature. 1998;393:702-4. https://doi.org/10.103 8/31508.

83. Fitzpatrick AWP, Falcon B, He S, Murzin AG, Murshudov G, Garringer HJ, et al. Cryo-EM structures of tau filaments from Alzheimer's disease. Nature. 2017;547:185-90. https://doi.org/10.1038/nature23002.

84. Neary D, Snowden JS, Gustafson L, Passant U, Stuss D, Black S, et al. Frontotemporal lobar degeneration: a consensus on clinical diagnostic criteria. Neurology. 1998;51:1546-54. https://doi.org/10.1212/WNL.51.6.1546.

85. Sebastián-Serrano Á, De Diego-García L, Díaz-Hernández M. The neurotoxic role of extracellular TAU protein. Int J Mol Sci. 2018;19:998.

86. Ittner A, Chua SW, Bertz J, Volkerling A, van der Hoven J, Gladbach A, et al. Site-specific phosphorylation of tau inhibits amyloid- $\beta$ toxicity in Alzheimer's mice. Science. 2016;354:904-8.

87. Maia LF, Kaeser SA, Reichwald J, Hruscha M, Martus P, Staufenbiel M, et al. Changes in amyloid- $\beta$ and Tau in the cerebrospinal fluid of transgenic mice overexpressing amyloid precursor protein. Sci Transl Med. 2013;5:194re2. https://doi.org/10.1126/scitrans/med.3006446.

88. Schelle J, Häsler LM, Göpfert JC, Joos TO, Vanderstichele H, Stoops E, et al. Prevention of tau increase in cerebrospinal fluid of APP transgenic mice suggests downstream effect of BACE1 inhibition. Alzheimers Dement. 2017; 13:701-9. https://doi.org/10.1016/j.jalz.2016.09.005.

89. Mattsson-Carlgren N, Andersson E, Janelidze S, Ossenkoppele R, Insel P, Strandberg $O$, et al. $A \beta$ deposition is associated with increases in soluble and phosphorylated tau that precede a positive Tau PET in Alzheimer's disease. Sci Adv. 2020;6:eaaz2387. https://doi.org/10.1126/sciadv.aaz2387.

90. Karikari TK, Pascoal TA, Ashton NJ, Janelidze S, Benedet AL, Rodriguez JL, et al. Blood phosphorylated tau 181 as a biomarker for Alzheimer's disease: a diagnostic performance and prediction modelling study using data from four prospective cohorts. Lancet Neurol. 2020;19:422-33.

91. Moloney CM, Lowe VJ, Murray ME. Visualization of neurofibrillary tangle maturity in Alzheimer's disease: a clinicopathologic perspective for biomarker research. Alzheimers Dement. 2021; https://doi.org/10.1002/a Iz.12321.

92. Dujardin S, Commins C, Lathuiliere A, Beerepoot P, Fernandes AR, Kamath TV, et al. Tau molecular diversity contributes to clinical heterogeneity in Alzheimer's disease. Nat Med. 2020;26:1256-63. https://doi.org/10.1038/s41 591-020-0938-9.

93. Mori H, Hosoda K, Matsubara E, Nakamoto T, Furiya $Y$, Endoh R, et al. Tau in cerebrospinal fluids: establishment of the sandwich ELISA with antibody specific to the repeat sequence in tau. Neurosci Lett. 1995;186:181-3.

94. Johnson GV, Seubert P, Cox TM, Motter R, Brown JP, Galasko D. The tau protein in human cerebrospinal fluid in Alzheimer's disease consists of proteolytically derived fragments. J Neurochem. 1997;68:430-3.

95. Galasko D, Clark C, Chang L, Miller B, Green RC, Motter R, et al. Assessment of CSF levels of tau protein in mildly demented patients with Alzheimer's disease. Neurology. 1997;48:632-5.

96. Price JL, Morris JC. Tangles and plaques in nondemented aging and "preclinical" Alzheimer's disease. Ann Neurol. 1999;45:358-68. https://doi. org/10.1002/1531-8249(199903)45:3<358::AID-ANA12>3.0.CO;2-X.

97. Fu H, Possenti A, Freer R, Nakano Y, Hernandez Villegas NC, Tang M, et al. A tau homeostasis signature is linked with the cellular and regional vulnerability of excitatory neurons to tau pathology. Nat Neurosci. 2019;22: 47-56.

98. Leyns CEG, Gratuze M, Narasimhan S, Jain N, Koscal L, Jiang H, et al. TREM2 function impedes tau seeding in neuritic plaques. Nat Neurosci. 2019; https://doi.org/10.1038/s41593-019-0433-0.

99. Schindler SE, Bollinger JG, Ovod V, Mawuenyega KG, Li Y, Gordon BA, et al. High-precision plasma $\beta$-amyloid $42 / 40$ predicts current and future brain amyloidosis Class of Evidence Criteria for rating therapeutic and diagnostic studies. Neurology. 2019; https://doi.org/10.1212/WNL.0000000000008081.

100. Thijssen EH, Verberk IMW, Vanbrabant J, Koelewijn A, Heijst H, Scheltens P, et al. Highly specific and ultrasensitive plasma test detects Abeta(1-42) and Abeta(1-40) in Alzheimer's disease. Sci Rep. 2021;11:9736. https://doi.org/1 0.1038/s41598-021-89004-X.

101. De Meyer S, Schaeverbeke JM, Verberk IMW, Gille B, De Schaepdryver M, Luckett ES, et al. Comparison of ELISA- and SIMOA-based quantification of plasma $A \beta$ ratios for early detection of cerebral amyloidosis. Alzheimers Res Ther. 2020;12:1-16. https://doi.org/10.1186/s13195-020-00728-w.

102. Streit WJ. Microglia and Alzheimer's disease pathogenesis. J Neurosci Res. 2004;77:1-8. https://doi.org/10.1002/jnr.20093. 
103. Broussard GJ, Mytar J, Li RC, Klapstein GJ. The role of inflammatory processes in Alzheimer's disease. Inflammopharmacology. 2012;20:109-26. https://doi.org/10.1007/s10787-012-0130-z.

104. Bales KR, Du Y, Holtzman D, Cordell B, Paul SM. Neuroinflammation and Alzheimer's disease: critical roles for cytokine/Aß-induced glial activation, NF-KB, and apolipoprotein E. Neurobiol Aging. 2000;21:427-32.

105. Malik M, Parikh I, Vasquez JB, Smith C, Tai L, Bu G, et al. Genetics ignite focus on microglial inflammation in Alzheimer's disease. Mol Neurodegener. 2015;10:52. https://doi.org/10.1186/s13024-015-0048-1.

106. Landel V, Baranger K, Virard I, Loriod B, Khrestchatisky M, Rivera S, et al. Temporal gene profiling of the 5XFAD transgenic mouse model highlights the importance of microglial activation in Alzheimer's disease. Mol Neurodegener. 2014;9:33. https://doi.org/10.1186/1750-1326-9-33.

107. González-Scarano F, Baltuch G. Microglia as mediators of inflammatory and degenerative diseases. Annu Rev Neurosci. 1999;22:219-40. https://doi.org/1 0.1146/annurev.neuro.22.1.219.

108. Wegiel J, Wang KC, Imaki H, Rubenstein R, Wronska A, Osuchowski M, et al. The role of microglial cells and astrocytes in fibrillar plaque evolution in transgenic APPSW mice. Neurobiol Aging. 2001;22:49-61.

109. Hyman BT, Phelps CH, Beach TG, Bigio EH, Cairns NJ, Carrillo MC, et al. National Institute on Aging-Alzheimer's Association guidelines for the neuropathologic assessment of Alzheimer's disease. Alzheimers Dement 2012:8:1-13.

110. Stalder M, Deller T, Staufenbiel M, Jucker M. 3D-Reconstruction of microglia and amyloid in APP23 transgenic mice: no evidence of intracellular amyloid. Neurobiol Aging. 2001;22:427-34

111. Ulrich JD, Ulland TK, Colonna M, Holtzman DM. Elucidating the role of TREM2 in Alzheimer's disease. Neuron. 2017;94:237-48. https://doi.org/10.1 016/j.neuron.2017.02.042

112. Gratuze M, Leyns CEG, Holtzman DM. New insights into the role of TREM2 in Alzheimer's disease. Mol Neurodegener. 2018;13:1-16. https://doi.org/1 0.1186/s13024-018-0298-9.

113. Wang Y, Ulland TK, Ulrich JD, Song W, Tzaferis JA, Hole JT, et al. TREM2mediated early microglial response limits diffusion and toxicity of amyloid plaques. J Exp Med. 2016;213:667-75. https://doi.org/10.1084/jem.20151948.

114. Shi Y, Yamada K, Liddelow SA, Smith ST, Zhao L, Luo W, et al. ApoE4 markedly exacerbates tau-mediated neurodegeneration in a mouse mode of tauopathy. Nature. 2017:549:523-7. https://doi.org/10.1038/nature24016.

115. de Jong $D$, Jansen $R$, Hoefnagels W, Jellesma-Eggenkamp M, Verbeek M, Borm G, et al. No effect of one-year treatment with indomethacin on Alzheimer's disease progression: a randomized controlled trial. PLoS One. 2008;3:e1475. https://doi.org/10.1371/journal.pone.0001475.

116. Aisen PS, Schmeidler J, Pasinetti GM. Randomized pilot study of nimesulide treatment in Alzheimer's disease. Neurology. 2002;58:1050-4. https://doi. org/10.1212/WNL.58.7.1050

117. Scharf S, Mander A, Ugoni A, Vajda F, Christophidis N. A double-blind, placebo-controlled trial of diclofenac/misoprostol in Alzheimer's disease. Neurology. 1999:53:197-201. https://doi.org/10.1212/wnl.53.1.197.

118. Group AR, Meinert CL, McCaffrey LD, Breitner JC. Alzheimer's disease antiinflammatory prevention trial: design, methods, and baseline results. Alzheimers Dement. 2009:5:93-104. https://doi.org/10.1016/j.jalz.2008.09.004.

119. Breitner JC, Baker LD, Montine TJ, Meinert CL, Lyketsos CG, Ashe KH, et al. Extended results of the Alzheimer's disease anti-inflammatory prevention trial. Alzheimers Dement. 2011;7:402-11. https://doi.org/10.1016/j.jalz.201 0.12 .014 .

120. Group TADAPTR. Results of a follow-up study to the randomized Alzheimer's Disease Anti-inflammatory Prevention Trial (ADAPT). Alzheimers Dement. 2013;9:714-23. https://doi.org/10.1016/j.jalz.2012.11.012.

121. Perez SE, Nadeem M, He B, Miguel JC, Malek-Ahmadi MH, Chen K, et al. Neocortical and hippocampal TREM2 protein levels during the progression of Alzheimer's disease. Neurobiol Aging. 2017;54:133-43. https://doi.org/10.1 016/j.neurobiolaging.2017.02.012.

122. Yeh FL, Hansen DV, Sheng M. TREM2, microglia, and neurodegenerative diseases. Trends Mol Med. 2017;23:512-33.

123. Leyns CEG, Ulrich JD, Finn MB, Stewart FR, Koscal LJ, Serrano JR, et al. TREM2 deficiency attenuates neuroinflammation and protects against neurodegeneration in a mouse model of tauopathy. Proc Natl Acad Sci U S A. 2017;114:11524-9. https://doi.org/10.1073/pnas.1710311114.

124. Gratuze M, Leyns CEG, Sauerbeck AD, St-Pierre MK, Xiong M, Kim N, et al. Impact of TREM2R47H variant on tau pathology-induced gliosis and neurodegeneration. J Clin Invest. 2020;130:4954-68.
125. Dorey E, Chang N, Liu QY, Yang Z, Zhang W. Apolipoprotein E, amyloidbeta, and neuroinflammation in Alzheimer's disease. Neurosci Bull. 2014;30: 317-30. https://doi.org/10.1007/s12264-013-1422-z.

126. Harris FM, Brecht WJ, Xu Q, Mahley RW, Huang Y. Increased tau phosphorylation in apolipoprotein E4 transgenic mice is associated with activation of extracellular signal-regulated kinase. Modulation by zinc. J Biol Chem. 2004;279:44795-801. https://doi.org/10.1074/jbc.M408127200.

127. Farrer LA. Effects of age, sex, and ethnicity on the association between apolipoprotein E genotype and Alzheimer disease. JAMA. 1997;278:1349. https://doi.org/10.1001/jama.1997.03550160069041.

128. Yamazaki Y, Painter MM, Bu G, Kanekiyo T. Apolipoprotein E as a therapeutic target in Alzheimer's disease: a review of basic research and clinical evidence. CNS Drugs. 2016;30:773-89. https://doi.org/10.1007/s40263-016-03 61-4.

129. Safieh M, Korczyn AD, Michaelson DM. ApoE4: an emerging therapeutic target for Alzheimer's disease. BMC Med. 2019;17:1-17. https://doi.org/10.11 86/s12916-019-1299-4.

130. Williams T, Borchelt DR, Chakrabarty P. Therapeutic approaches targeting Apolipoprotein e function in Alzheimer's disease. Mol Neurodegener. 2020; 15:8. https://doi.org/10.1186/s13024-020-0358-9.

131. Hendrie HC, Murrell J, Baiyewu O, Lane KA, Purnell C, Ogunniyi A, et al. APOE $\varepsilon 4$ and the risk for Alzheimer disease and cognitive decline in African Americans and Yoruba. Int psychogeriatrcs. 2014;26:977-85. https://doi.org/1 $0.1017 /$ S1041610214000167.

132. Blue EE, Horimoto ARVR, Mukherjee S, Wijsman EM, Thornton TA. Local ancestry at APOE modifies Alzheimer's disease risk in Caribbean Hispanics. Alzheimers Dement. 2019;15(12):1524-32.

133. Hashimoto T, Serrano-Pozo A, Hori Y, Adams KW, Takeda S, Banerji AO, et al. Apolipoprotein e, especially apolipoprotein E4, increases the oligomerization of amyloid $\beta$ peptide. J Neurosci. 2012;32:15181-92. https:// doi.org/10.1523/JNEUROSCI.1542-12.2012.

134. Christensen DZ, Schneider-Axmann T, Lucassen PJ, Bayer TA, Wirths O. Accumulation of intraneuronal $A \beta$ correlates with ApoE4 genotype. Acta Neuropathol. 2010;119:555-66. https://doi.org/10.1007/s00401-010-0666-1.

135. Halliday MR, Rege SV, Ma Q, Zhao Z, Miller CA, Winkler EA, et al. Accelerated pericyte degeneration and blood-brain barrier breakdown in apolipoprotein E4 carriers with Alzheimer's disease. J Cereb Blood Flow Metab. 2016;36: 216-27. https://doi.org/10.1038/jcbfm.2015.44.

136. Chalmers K, Wilcock GK, Love S. APOE \&4 influences the pathological phenotype of Alzheimer's disease by favouring cerebrovascular over parenchymal accumulation of $A \beta$ protein. Neuropathol Appl Neurobiol. 2003;29:231-8. https://doi.org/10.1046/j.1365-2990.2003.00457.x.

137. Vitek MP, Brown CM, Colton CA. APOE genotype-specific differences in the innate immune response. Neurobiol Aging. 2009;30:1350-60. https://doi. org/10.1016/j.neurobiolaging.2007.11.014.

138. Reiman EM, Arboleda-Velasquez JF, Quiroz YT, Huentelman MJ, Beach TG, Caselli RJ, et al. Exceptionally low likelihood of Alzheimer's dementia in APOE2 homozygotes from a 5,000-person neuropathological study. Nat Commun. 2020;11:1-11. https://doi.org/10.1038/s41467-019-14279-8.

139. Woo D, Sauerbeck LR, Kissela BM, Khoury JC, Szaflarski JP, Gebel J, et al. Genetic and environmental risk factors for intracerebral hemorrhage: preliminary results of a population-based study. Stroke. 2002;33:1190-5. https://doi.org/10.1161/01.STR.0000014774.88027.22.

140. O'Donnell HC, Rosand J, Knudsen KA, Furie KL, Segal AZ, Chiu RI, et al. Apolipoprotein $\mathrm{E}$ genotype and the risk of recurrent lobar intracerebral hemorrhage. N Engl J Med. 2000;342:240-5. https://doi.org/10.1056/nejm2 00001273420403.

141. Schilling S, DeStefano AL, Sachdev PS, Choi SH, Mather KA, DeCarli CD, et al. APOE genotype and MRI markers of cerebrovascular disease. Neurology. 2013;81:292-300. https://doi.org/10.1212/WNL.0b013e31829bfda4

142. Nicoll JAR, Burnett C, Love S, Graham DI, Dewar D, Ironside JW, et al. High frequency of apolipoprotem E $\varepsilon 2$ allele in hemorrhage due to cerebral amyloid angiopathy. Ann Neurol. 1997;41:716-21. https://doi.org/10.1002/a na.410410607.

143. Nelson PT, Pious NM, Jicha GA, Wilcock DM, Fardo DW, Estus S, et al. APOE$\varepsilon 2$ and APOE- $\varepsilon 4$ correlate with increased amyloid accumulation in cerebral vasculature. J Neuropathol Exp Neurol. 2013;72:708-15. https://doi.org/10.1 097/NEN.0b013e31829a25b9.

144. Black JRM, Clark SJ. Age-related macular degeneration: genome-wide association studies to translation. Genet Med. 2016;18:283-9. https://doi. org/10.1038/gim.2015.70. 
145. Klaver CCW, Kliffen M, Van Duijn CM, Hofman A, Cruts M, Grobbee DE, et al. Genetic association of apolipoprotein $\mathrm{E}$ with age-related macular degeneration. Am J Hum Genet. 1998;63:200-6. https://doi.org/10.1086/301901.

146. Arboleda-Velasquez JF, Lopera F, O'Hare M, Delgado-Tirado S, Marino C, Chmielewska N, et al. Resistance to autosomal dominant Alzheimer's disease in an APOE3 Christchurch homozygote: a case report. Nat Med. 2019; https://doi.org/10.1038/s41591-019-0611-3.

147. Folstein MF, Folstein SE, McHugh PR. "Mini-mental state": a practical method for grading the cognitive state of patients for the clinician. J Psychiatr Res. 1975;12:189-98. https://doi.org/10.1016/0022-3956(75)90026-6.

148. Farrimond LE, Roberts E, McShane R. Memantine and cholinesterase inhibitor combination therapy for Alzheimer's disease: a systematic review. BMJ Open. 2012;2:e000917. https://doi.org/10.1136/bmjopen-2012-000917.

149. Cummings JL, Tong G, Ballard C. Treatment combinations for Alzheimer's disease: current and future pharmacotherapy options. J Alzheimers Dis. 2019;67:779-94. https://doi.org/10.3233/JAD-180766.

150. Selkoe DJ, Hardy J. The amyloid hypothesis of Alzheimer's disease at 25 years. EMBO Mol Med. 2016;8:595-608. https://doi.org/10.15252/emmm.201 606210.

151. Panza F, Lozupone M, Solfrizzi V, Sardone R, Piccininni C, Dibello V, et al. BACE inhibitors in clinical development for the treatment of Alzheimer's disease. Expert Rev Neurother. 2018;18:847-57. https://doi.org/10.1080/1473 7175.2018 .1531706 .

152. Gauthier S, Alam J, Fillit H, Iwatsubo T, Liu-Seifert H, Sabbagh M, et al. Combination therapy for Alzheimer's Disease: perspectives of the EU/US CTAD Task Force. J Prev Alzheimers Dis. 2019;6:164-8. https://doi.org/10.142 83/jpad.2019.12.

153. Rynearson KD, Ponnusamy M, Prikhodko O, Xie Y, Zhang C, Nguyen P, et al. Preclinical validation of a potent $\gamma$-secretase modulator for Alzheimer's disease prevention. J Exp Med. 2021;218:e20202560. https://doi.org/10.1084/ JEM.20202560.

154. Tomaszewski S, Gauthier S, Wimo A, Rosa-Neto P. Combination therapy of anti-Tau and anti-amyloid drugs for disease modification in early-stage Alzheimer's disease: socio-economic considerations modeled on treatments for tuberculosis, HIV/AIDS and Breast Cancer. J Prev Alzheimers Dis. 2016:3: 164-72. https://doi.org/10.14283/jpad.2015.85.

155. Salloway SP, Sevingy J, Budur K, Pederson JT, DeMattos RB, Von Rosenstiel P, et al. Advancing combination therapy for Alzheimer's disease. Alzheimer's Dement Transl Res Clin Interv. 2020;6:-e12073. https://doi.org/10.1002/ trc2.12073.

156. Robinson JL, Richardson H, Xie SX, Suh E, Van Deerlin VM, Alfaro B, et al. The development and convergence of co-pathologies in Alzheimer's disease. Brain. 2021;144:953-62. https://doi.org/10.1093/brain/awaa438.

157. Spina S, La Joie R, Petersen C, Nolan AL, Cuevas D, Cosme C, et al. Comorbid neuropathological diagnoses in early versus late-onset Alzheimer's disease. Brain. 2021; https://doi.org/10.1093/brain/awab099.

158. Twohig D, Nielsen HM. a-Synuclein in the pathophysiology of Alzheimer's disease. Mol Neurodegener. 2019;14:1-19. https://doi.org/10.1186/s13024-01 9-0320-x.

159. Ngandu T, Lehtisalo J, Solomon A, Levälahti E, Ahtiluoto S, Antikainen R, et al. A 2 year multidomain intervention of diet, exercise, cognitive training, and vascular risk monitoring versus control to prevent cognitive decline in at-risk elderly people (FINGER): a randomised controlled trial. Lancet. 2015; 385:2255-63. https://doi.org/10.1016/S0140-6736(15)60461-5.

160. Baker LD, Espeland MA, Kivipelto M, Whitmer RA, Snyder HM, Carrillo MC, et al. U.S. POINTER (USA). Alzheimers Dement. 2020;16:e46951. https://doi. org/10.1002/alz.046951.

161. Kivipelto M, Mangialasche F, Snyder HM, Allegri R, Andrieu S, Arai H, et al. World-Wide FINGERS Network: a global approach to risk reduction and prevention of dementia. Alzheimers Dement. 2020;16:1078-94. https://doi. org/10.1002/alz.12123.

162. Vos SJB, Xiong C, Visser PJ, Jasielec MS, Hassenstab J, Grant EA, et al. Preclinical Alzheimer's disease and its outcome: a longitudinal cohort study. Lancet Neurol. 2013;12:957-65. https://doi.org/10.1016/S1474-4422(13)70194-7.

\section{Publisher's Note}

Springer Nature remains neutral with regard to jurisdictional claims in published maps and institutional affiliations.

\section{Ready to submit your research? Choose BMC and benefit from:}

- fast, convenient online submission

- thorough peer review by experienced researchers in your field

- rapid publication on acceptance

- support for research data, including large and complex data types

- gold Open Access which fosters wider collaboration and increased citations

- maximum visibility for your research: over $100 \mathrm{M}$ website views per year

At $\mathrm{BMC}$, research is always in progress.

Learn more biomedcentral.com/submissions 